\title{
Erwägungen zur Korrelation mittelpleistozäner Relikte des Rheingletschers mit der Nordschweizer Stratigraphie
}

Oskar Keller

How to cite:

Kurzfassung:

Abstract:

Keywords:
KeLLER, O. (2014): Erwägungen zur Korrelation mittelpleistozäner Relikte des Rheingletschers mit der Nordschweizer Stratigraphie. - E\&G Quaternary Science Journal, 63 (1): 19-43. DOI: 10.3285/eg.63.1.02

Für die Nordschweiz wird in Preusser, Graf, Keller, Krayss \& Schlüchter (2011) dargelegt, dass vor den bekannten Glazialen Würm = Birrfeld und Riss = Beringen zwei (eventuell drei) weitere mittelpleistozäne Glaziale einzuschieben sind: Habsburg und Möhlin. In dieser Arbeit werden an ausgewählten Schlüsselstellen in Süddeutschland litho- und morphostratigraphische Befunde ausgewertet, die es ermöglichen diese zwei neu eingeführten Glaziale auch auf den Rheingletscher zu übertragen.

Dem Zeitraum der Deckenschotter-Eiszeiten schliesst sich die Periode der MPR (Mittelpleistozäne Reorganisation) mit einer markanten fluvialen Ausräumung des Bodenseegebiets an. Es wird gezeigt, dass die Gletscher der nachfolgenden mittelpleistozänen Becken-Eiszeiten das übertiefte Bodenseebecken ausschürften. Die älteste dieser Eiszeiten wird als Größtes Rheinisches Glazial (GRG) = Möhlin bezeichnet und entspricht dem von ELLWANGER (2003) eingeführten Hosskirch. Ihm können im nördlichen Rheingletschergebiet alle äußersten glaziären Bildungen zugewiesen werden. Im Nordwesten wurden diese früher als risszeitlich interpretiert, im Nordosten hingegen als mindelzeitlich. Das GRG ist nachweisbar älter als Riss, aber jünger als die Jüngeren Deckenschotter. Mindel im Nordosten des Rheingletschers würde daher zur Becken-Eiszeit.

Das Habsburg-Glazial erreichte in der Nordschweiz ungefähr Ausmaße wie Würm. Im Rheingletschergebiet konnten in der entsprechenden Bandbreite, aber auch ausserhalb Zeugen und/oder Indizien gefunden werden, die dieses Glazial wahrscheinlich machen. Bisher ist diese eiszeitliche Großvergletscherung im nördlichen Rheingletschergebiet nicht erkannt worden, weil ihre Hinterlassenschaften von den nachfolgenden Glazialen Riss und Würm großenteils zerstört wurden.

Für die chronostratigraphische Einordnung des Größten Rheinischen Glazials GRG sowie des Habsburg-Glazials können zwischengeschaltete Interglaziale als Zeitmarken beigezogen werden: IG Unterpfauzenwald - GRG - IG Holstein - Habsburg - IG Meikirch - Riss - IG Eem. Demgemäss ergibt sich folgende zeitliche Ordnung für die Glaziale: GRG \pm 350 ka BP (MIS 10), Habsburg \pm 250 ka BP (MIS 8), Riss \pm 150 ka BP (MIS 6)

Considerations on the correlation of relics of the Rhine Glacier in the Middle Pleistocene with the stratigraphy of Northern Switzerland

In the glaciation history of Switzerland (Preusser, Graf, Keller, Krayss \& Schlüchter 2011) is shown that two (possibly three) older glacials had happened before the well known glacials Würm = Birrfeld and Riss = Beringen. These are the Habsburg- and the Möhlin-Glacials. In this paper selected key regions in Southern Germany are analysed litho- and morphostratigraphically. This analysis enables us to find the two older glacials proved also at the Rhine Glacier.

The period of the „Deckenschotter"-glaciations is followed by a time of striking fluvial erosion (MPR = Middle Pleistocene Reorganisation) in the region of Lake Constance. It is demonstrated that the glaciers of the subsequent Middle Pleistocene glacials exarated the overdeepened Lake Constance basin. The oldest of these „Becken-Glacials" is named „Größtes Rheinisches Glazial“ (GRG) = Möhlin in the northern part of Switzerland. It corresponds to the Hosskirch introduced by ElLwANGER (2003). In the northern Rhine Glacier region the most external glacial deposits belong to this glaciation. Earlier in the northwestern part these deposits are interpreted as Riss-Glacial, but in the northeast as Mindel-Glacial. The GRG evidently must be older than Riss, but younger than the „Younger Deckenschotter“. Therefore Mindel in the northeastern region would be a Becken-Glacial.

In the northern part of Switzerland the Habsburg-Glacial nearly reached the extension of the Würm-Glacial. In the region of the Rhine Glacier references and/or indications of the Habsburg-Glacial could be found in a band width corresponding to the Würm, but outside it as well. In the northern region of the Rhine Glacier this vast glaciation has not been discovered up to now because the subsequent glacials Riss and Würm mainly destroyed its relics.

To classify the „Greatest Rhine Glacial“ GRG as well as the Habsburg-Glacial chronologically interpolated interglacials with time marks can be applied: IG Unterpfauzenwald - GRG - IG Holstein - Habsburg - IG Meikirch - Riss - IG Eem. Accordingly a temporal classification for the glacials results as follows: (GRG) \pm 350 ka BP (MIS 10), Habsburg \pm 250 ka BP (MIS 8), Riss \pm 150 ka BP (MIS 6).

Alpine foreland, Rhine Glacier, chronostratigraphy, glacial deposits, glacial drainage 


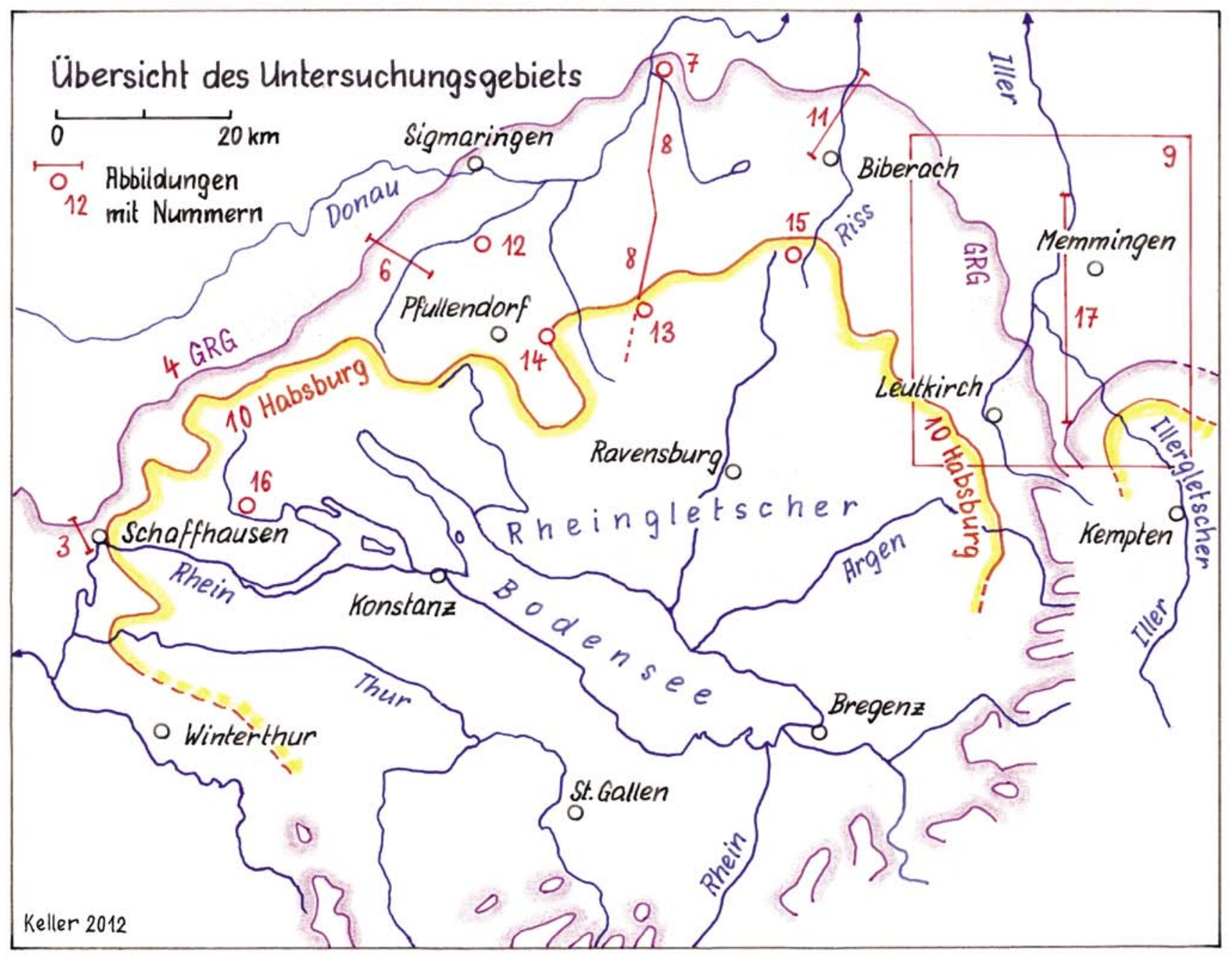

Abb. 1: Übersichtskarte des Untersuchungsgebiets des nördlichen Rheingletschers. Rot = Nummern der Abbildungen.

Fig. 1: Overview map of the study region of the northern Rhine Glacier. Red = Numbers of figures.

\section{Einführung und Zielsetzung}

Seit wenigen Jahren liegen drei Publikationen vor, die sich mit dem mittel- und spätpleistozänen Quartär in der Nordschweiz befassen. Als Beitrag zur Geologischen Karte der Schweiz erschien von GRAF (2009a) eine umfassende Untersuchung zur Lithostratigraphie, Morphogenese und Gliederung jener pleistozänen Bildungen in der Nordschweiz, die bisher den Hoch- und Niederterrassen zugeordnet wurden. Eine zusammenfassende Neuinterpretation von sieben Schlüsselregionen, zu denen eine Reihe neuerer Forschungsergebnisse vorlag (Graf, Hofmann, Kempf, Preusser, Schindler, Schlüchter, Wyssling u. a.), erarbeiteten Keller \& KRAYsS (2010). Sie konnten sich dabei insbesondere auch auf Befunde von Graf (2009a) stützen, die ihnen ab 2002 in einem Typoskript zur Einsicht offen standen.

In der jüngsten Publikation legen Preusser, Graf, KeLLER, KRAYSS \& SCHLÜChtER (2011) eine revidierte Vergletscherungsgeschichte der nördlichen Schweiz vor. Den derzeitigen Forschungsstand hinsichtlich der Schweizer Chronostratigraphie zeigt das Schema der Abb. 2, das hier aus Preusser et al. (2011, Fig. 19) unverändert übernommen wird. Demnach ist eine Gruppe frühpleistozäner Glaziale (Höhere und Tiefere Deckenschotter) durch eine Periode bedeutender Ausräumung (MPR = Mittelpleistozäne Reorganisation) von den mittelpleistozänen Bildungen getrennt. Das Mittel- und Spätpleistozän enthält vier oder fünf Großvergletscherungen des Alpenvorlandes, die gemäß einem Vorschlag von Graf (2009a) als Möhlin-, Habsburg-, Hagenholz-, Beringen- und Birrfeld-Glazial angesprochen werden. Nachdem das stratigraphische Schema gemäss Abb. 2 als Kompilation der an Preusser et al. (2011) Beteiligten zu verstehen ist, wird in der vorliegenden Arbeit die dort von Keller und Krayss vertretene Auffassung zu Grunde gelegt. Im Unterschied zu GRAF (2009b), der in der Korrelationstabelle Tafel 19 die Habsburg-Vergletscherung als Wiedervorstoß der Möhlin-Vergletscherung aufführt, ist das HabsburgEreignis als selbständige Eiszeit zu verstehen. Im Weiteren wird die im Schema Abb. 2 als fraglich markierte HagenholzGlaciation lediglich als Aufbauphase zur Beringen-Glaciation interpretiert.

Für das süddeutsche Gebiet des Rheingletschers sind neuerdings zwei Artikel publiziert von ElLWANGER et al. (2011a) zur Quartärgeologie des Rheingletschergebiets und von ELLWANGER et al. (2011b) zum Quartär des süddeutschen Alpenvorlandes, in denen der derzeitige Stand der Kenntnisse aufgezeigt wird. Es wird eine Gliederung des Mittel- und Spätpleistozäns präsentiert, bei der Würm als letzte, Riss als 
zweitletzte und, vor kurzem neu eingeführt (ELLWANGER in LGRB 2003), Hosskirch als drittletzte und grösste Vergletscherung betrachtet werden.

Das gesamte rheinische hydrographische System von der Aare bis zum Alpenrhein bildet bezüglich der Topographie eine Einheit, charakterisiert durch tief ausgeschürfte Auslasstäler aus den Alpen und stark übertiefte Vorlandbecken. Unzweifelhaft ist das Bodenseebecken, wenn auch besonders ausgedehnt, Teil dieser glazial ausgeformten Großregion. In Anbetracht des vorstehend erwähnten Kenntnisstandes zu den mittel- und spätpleistozänen Eiszeiten in der Nordschweiz liegt es auf der Hand zu versuchen diese Erkenntnisse auch im nördlichen Rheingletscherraum anzuwenden. Gemäss LGRB (2003), VILLINGER (2011) dürfte eine Entsprechung des nordschweizerischen Birrfeld mit Würm, Beringen mit Riss und Möhlin mit Hosskirch anzunehmen sein.

Bereits in den 1990er Jahren wurde für den Rheingletscher im Bodenseeraum eine größte Vergletscherung nach der Deckenschotterzeit postuliert (KeLler 1994, KelLER \& KraYsS 1999), für die damals die Bezeichnung GHV (Größte Helvetische Vergletscherung) eingeführt worden ist. Sie wird von Graf (2009a) und Keller \& Krayss (2010) aufgrund ihrer äußersten Frontlage als Möhlin-Glazial bezeichnet und als Entsprechung zu Hosskirch gemäss EllwaNger (2003) und ELLWANGER et al. (2011a und b) betrachtet. Im vorliegenden Artikel wird sie für den Rheingletscher in ihren Ausmaßen, ihrem Frontverlauf, ihren proglazialen Relikten und in ihrer chronostratigraphischen Stellung diskutiert.

Zwischen die größte Vergletscherung = Möhlin und Riss = Beringen schiebt sich in der Nordschweiz das HabsburgGlazial ein, das aufgrund der dortigen Untersuchungen deutlich geringere Ausmaße aufwies als jene beiden Vergletscherungen (Graf 2009a, Keller \& Krayss 2010). Diese Habsburg-Vorlandvergletscherung wurde bisher im Rheingletschergebiet in Oberschwaben nicht identifiziert. Für sie sollen in dieser Arbeit Argumente beigebracht werden, die eine solche Vergletscherung als wahrscheinlich erscheinen lassen.

Die vorliegende Publikation beruht auf gemeinsamen Vorarbeiten und Begehungen mit Edgar Krayss bis Sommer 2011. Nun hat sich E. Krayss per Ende 2011 altershalber von der Weiterbearbeitung des Projekts „Rheingletscher in Oberschwaben“ zurückgezogen. Damit übernimmt der $\mathrm{Au}-$ tor O. Keller die alleinige Verantwortung für diese Veröffentlichung.

\section{Terminologie}

Mit der Publikation von Penck \& BrÜckner (1901/09, 396) lag ein Kärtchen im Massstab 1 : 700000 vor, in welchem der äußerste Eisrand des Rheingletschers nachgezeichnet ist. Das Moränen-Gebiet zwischen der Aitrach und dem Risstal wurde der Mindel-Eiszeit zugeordnet, dasjenige von dort bis zum Hegau der Riss-Eiszeit. Und so blieb es fast hundert Jahre.

Im Zuge der Neuordnung der Eiszeitgliederung im Schweizer Mittelland postulierte SCHLÜCHTER (1988, Fig. 1) vor dem bisherigen Riss eine viertletzte Eiszeit als Most Extensive Glaciation (MEG). In der Arbeit von Graf (2009a, Tab. 19) figuriert diese Größte Eiszeit unter dem Namen Möhlin-Eiszeit.

In ihrem Beitrag in den Erläuterungen zur Geologischen Übersichtskarte des Kantons Thurgau führten KeLLER \&

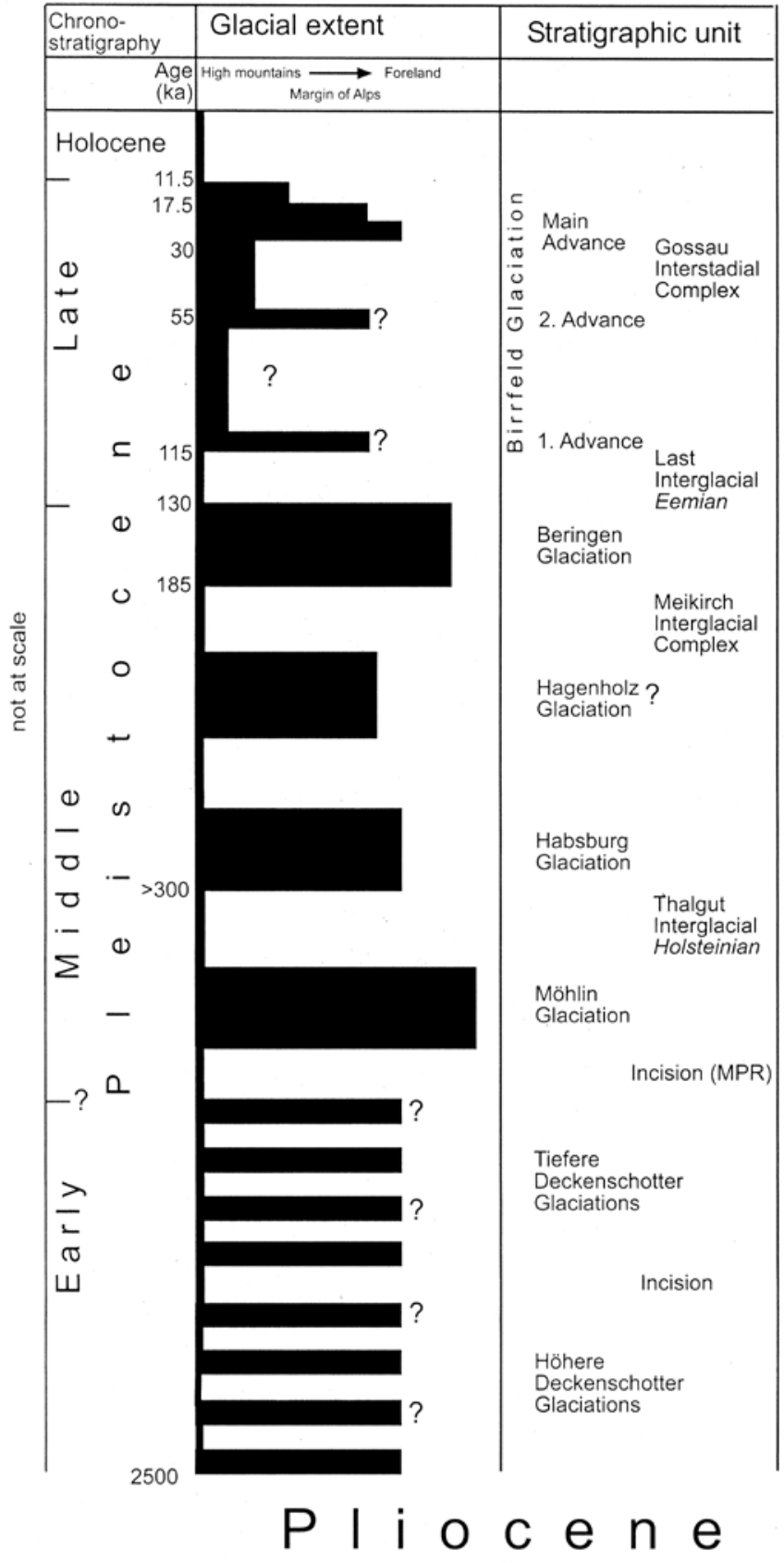

Abb. 2: Stratigraphisches Schema der Vergletscherungsgeschichte der Schweiz (nach PREUSSER et al. 2011).

Fig. 2: Stratigraphy scheme of the glaciation history of Switzerland (after PREUSSER et al. 2011).

KrAYss (1999) vor der Riss-Eiszeit eine Größte Helvetische Vergletscherung (GHV) ein, gültig für die Vorlandvergletscherungen der Nordschweiz und des Rheingletschers.

Ellwanger verwendete für die größte Vergletscherung verschiedene Bezeichnungen: Älteres Riss (Ellwanger 1995), MEG (ElLWANGER in LGRB 2003, 2005). Villinger (2011) bezeichnet die „drittletzte/größte Vergletscherung im Rheingletschergebiet" mit dem Namen Hosskirch. Dieser bezieht sich topographisch einerseits auf einen früher als Riss angesprochenen Geländestreifen zwischen Messkirch und Riedlingen und anderseits auf den externsten Gletscherrand vom Raum Biberach bis zum Aitrachtal, womit sämtliche äußersten Glazialrelikte der gleichen Eiszeit zugewiesen werden. Im Gelände-Abschnitt Riss-Aitrach wurden bisher die 


\title{
Glaziale Dynamik (Raum Schaffhausen)
}

\author{
Referenzen: Schindler 1985, Hofmann 1994, \\ Graf 2009, Keller \& Krayss 2010
}

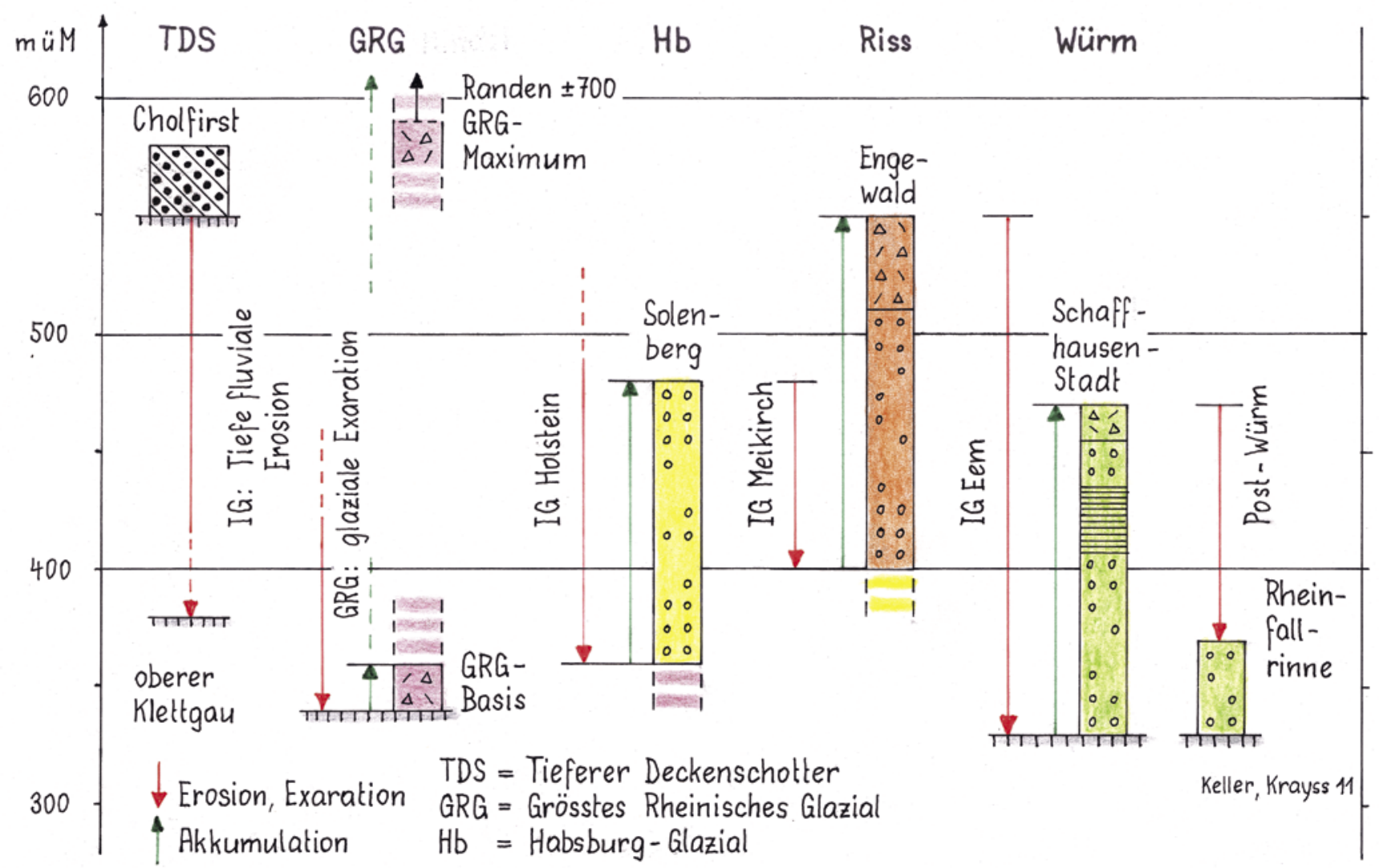

Abb. 3: Morphologische Dynamik der Eiszeiten mit Phasen der Akkumulation und Erosion.

Fig. 3: Morphological dynamics of the glacials shown by phases of accumulation and erosion.

entsprechenden Elemente Mindel zugeordnet. Das Bayerische Landesamt für Umwelt, Geologischer Dienst sowie auch Doppler et al. (2011) halten an den Bezeichnungen Mindel und Haslach für die größte Ausdehnung des Bayern zugewandten Rheingletschers fest.

Mit den Begriffen MEG, Möhlin, GHV, Hosskirch und Mindel liegen also im letzten Vierteljahrhundert mehrere Namen für die ausgedehnteste Vergletscherung von der Nordschweiz bis zur Iller vor. Aktuell wird im süddeutschen Raum im nördlichen Rheingletschergebiet für die größte Vergletscherung der Name „Hosskirch“ verwendet, in der Nordschweiz, inklusive Rheingletscher südlich und westlich des Bodensees, hingegen „Möhlin“. Das bedeutet, dass für dieselbe Vorlandvergletscherung zwei Bezeichnungen im Gebrauch sind. Es wird daher in dieser Arbeit hierfür die neutrale Sammelbezeichnung „Größtes Rheinisches Glazial GRG" verwendet.

Zwischen dem Größten Rheinischen Glazial = Möhlin und dem Riss-Glazial = Beringen ist in der Nordschweiz eine weitere Großvergletscherung des Vorlandes, das HabsburgGlazial erkannt worden (GrAF 2009b, Keller \& KraYss 2010). Für diese Vergletscherung, deren Nachweis hier für das nördliche Rheingletschergebiet angestrebt wird, findet vorläufig die Bezeichnung „Habsburg-Glazial“" Verwendung. Somit wird in der vorliegenden Arbeit für das Mittel- und Spätpleistozän hinsichtlich der Eiszeitengliederung folgende
Terminologie verwendet:

$\begin{array}{ll}\text { Nordschweiz: } & \text { Rheingletschergebiet: } \\ \text { Birrfeld } & \text { Würm } \\ \text { Beringen } & \text { Riss } \\ \text { Habsburg } & \text { Habsburg } \\ \text { Möhlin } & \text { GRG (Größtes Rheinisches Glazial) } \\ & \quad=\text { Hosskirch }\end{array}$

\section{Der Rheingletscher im Mittel- und Spätpleistozän 3.1 Geländestruktur}

Zwischen Berner Aaretal und Bodensee ist das Nordschweizer Alpenvorland durch ein tief reichendes fluviales Entwässerungssystem, das auf die niedrig gelegene Oberrheinische Tiefebene ausgerichtet ist, gekennzeichnet. Die Umlenkung des Alpenrheins weg von der Donau nach Westen zum Oberrhein (Keller 2009) führte zu einer massiven fluviatilen Durchtalung des Hochrhein- und des Aaresystems. Die mächtigen Eisströme der anschliessenden größten Vergletscherung schürften in der Folge die meisten übertieften Becken der Nord- und Ostschweiz aus, darunter insbesondere auch das ausgedehnte Bodenseebecken. Dieses nimmt eine Sonderstellung ein, indem die Entwässerung zwar nach Westen gerichtet war, aber während den Maximalständen der Vergletscherungen auch nordwärts in das hoch liegende danubische System übergriff. 


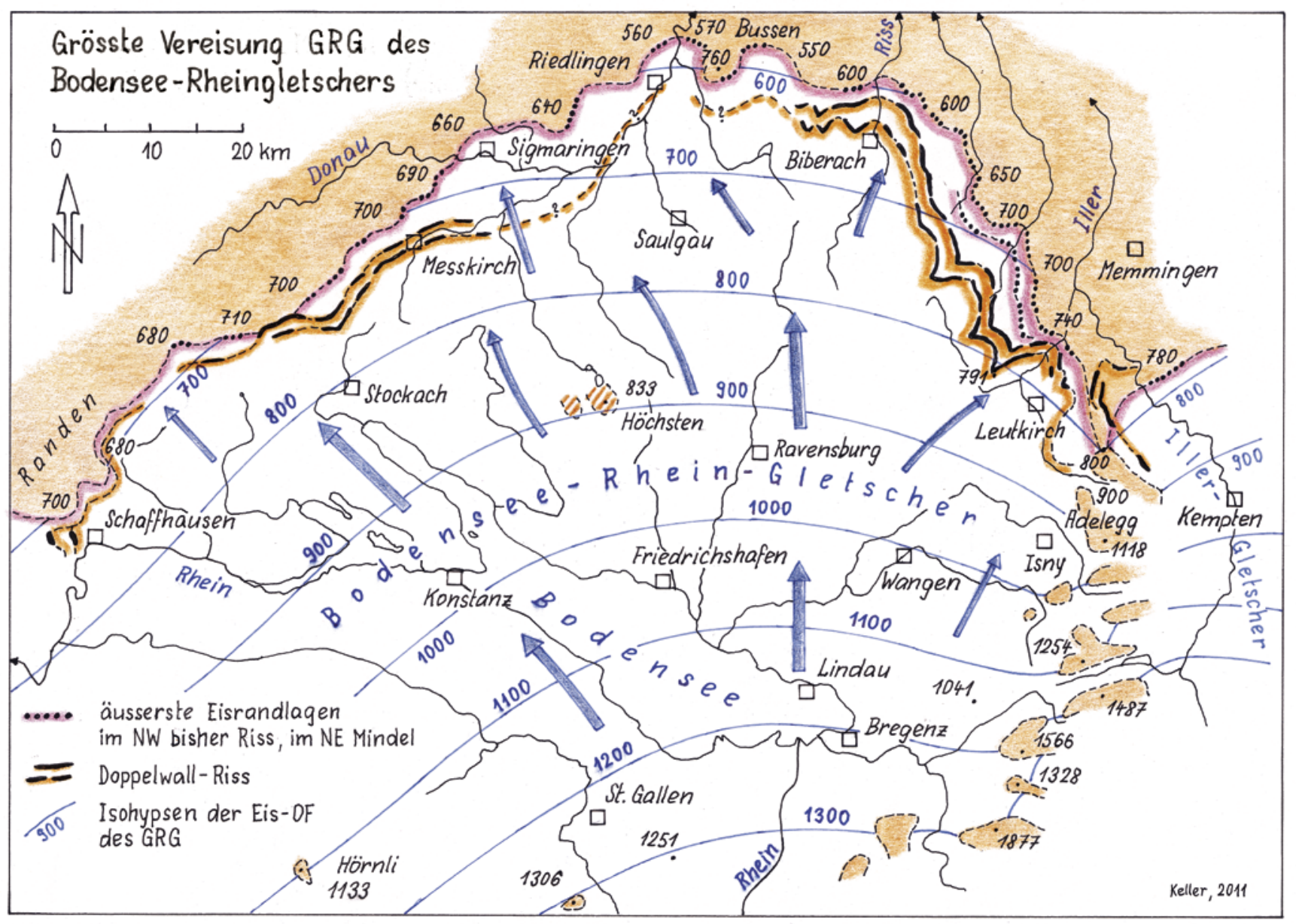

Abb. 4: Maximale Eisausdehnung des Grössten Rheinischen Glazials (GRG) im Vorland.

Fig. 4: Maximal ice extension of the Greatest Rhine-Glacial (GRG) in the foreland.

Eiszeiten, deren Eisströme den nördlichen Rand des Bodenseebeckens, die Wasserscheide zur Donau, überschritten, hinterliessen zur Donau hin glaziale Sedimente, den direkten Nachweis einer Gletscherpräsenz. Erreichten sie aber nicht diese Mindestausmaße, so konnten nur deren Schmelzwasserströme allenfalls kurzfristig Richtung Donau glazifluviale Sedimente ablagern. Lithostratigraphisch sind daher im Nord- und Ostsektor des Rheingletschers ausserhalb des Bodensee-Beckenrandes Eiszeiten mit geringeren Vergletscherungsausmaßen mit Hilfe glaziärer Sedimente nicht fassbar. Auch die Morphostratigraphie mit Terrasseneinschachtelungen und glazialen Serien ist kaum anwendbar.

\subsection{Glaziologie}

Vorlandvergletscherungen im Alpenrhein- und Bodenseeraum stellen sich dann ein, wenn im inneralpinen RheinEinzugsgebiet die regionale Schneegrenze von den interglazialen Hochlagen auf weniger als $1500 \mathrm{~m}$ ü. M. absinkt. Dadurch vergletschern die Alpentäler, deren Eisströme sich vereinigen und durch die Auslasstäler ins Vorland vorstoßen. Bei Schneegrenzen um 1000 m ü. M., wie sie beim Rheingletscher im letzten Glazial auftraten (KeLLER \& KRAYss 2005), baut sich ein das ganze Bodenseebecken bis zur Donau-Wasserscheide oder darüber hinaus erfüllender Eiskörper auf.

Bedingt durch die in den jüngeren Glazialen bereits niedrig gelegene Diffluenz von Sargans zweigt jeweils ein Ast des Rheingletschers westwärts ab, was zusammen mit dem Linthgletscher zu einem weiteren Vorlandgletscher im Limmat- und Glatttal-Gebiet führt. Die Ausmaße dieses LinthRheingletschers machten allerdings gegenüber dem Bodensee-Rheingletscher nur ca. 1/5 des eisbedeckten Gebietes aus (Keller \& Krayss 2005).

Rekonstruktionen und Berechnungen für das letzteiszeitliche Maximum des Bodensee-Rheingletschers ergaben für das Vorland ein vergletschertes Areal von $7200 \mathrm{~km}^{2}$ und ein Eisvolumen von $2400 \mathrm{~km}^{3}$. Die älteren mittelpleistozänen Vergletscherungen erreichten vergleichbare Ausmaße (Kapitel 4.4).

Der Aufbau der Vorlandvereisung im letzten Glazial nahm nur rund 5000 Jahre in Anspruch, das Rückschmelzen bis in die Alpentäler erfolgte in einem ebenfalls kurzen Zeitrahmen von ca. 6500 Jahren (Keller \& KraYss 1993, 2005). Es ist davon auszugehen, dass auch die mittelpleistozänen Eiszeiten für Auf- und Abbau ihrer Vorlandgletscher einen ähnlichen Zeitbedarf hatten.

Außer der größten Vergletscherung, die am Randen hoch hinaufreichte (HofmANn 1994, Keller \& KRAYss 2010), stiessen die Gletscher stets bis in den Raum Schaffhausen-Klettgau vor, von wo aus sie zum Hochrhein entwässerten. Über das Mittel- und Spätpleistozän hinweg ergibt sich ein charakteristisches Wechselspiel zwischen Akkumulation glazialer Sedimente und interglazialer Erosion (Abb. 3). Die kaltzeitliche Schüttung der Tieferen Deckenschotter erfolgte auf 
einem noch hoch liegenden Niveau um 500 m ü. M. auf dem Cholfirst südlich Schaffhausen. In der anschließenden Interglazialzeit führte die Umlenkung des Alpenrheins Richtung Westen (KELLER 2009) zu einer besonders ausgeprägten fluvialen Erosion, die MPR (Mittelpleistozäne Reorganisation) (SchlÜCHTER 1988), die im oberen Klettgau das Flussniveau um rund 200 Höhenmeter absenkte. Während den weiteren interglazialen Phasen war die Tiefenerosion stets markant, sodass die Entwässerungsbahnen des Rheins niedrig lagen. Sie verliefen anfangs durch den Klettgau, nach dem Riss durch das noch heute benutzte Rheintal. Die in jedem Glazial anfallenden Schotter und Feinsedimente wurden an den Gletscherfronten zu mächtigen Sedimentstapeln akkumuliert, bevor sie wieder interglazial mindestens teilweise erodiert wurden (GRAF 2009a, KELLER ひ KRAYSS 2010).

\section{Zum Größten Rheinischen Glazial [GRG]}

Aus den morphostratigraphischen Untersuchungen $\mathrm{zu}$ den jüngeren Eiszeiten in der Nordschweiz geht hervor, dass die ausgedehnteste Vergletscherung nicht Riss sein kann, sondern deutlich älter ist (Graf 2009a, Keller \& Krayss 2010, Preusser et al. 2011). Es ist zudem anzunehmen, dass dieses Glazial aufgrund von Paläoböden, Pollensequenzen und pflanzlichen Makroresten, die das Holstein-Interglazial widerspiegeln und im Hangenden über den Sedimenten dieser grössten Vergletscherung auftreten, älter sein muss als dieses Interglazial.

Im nördlichen Bodensee-Rheingletschergebiet wurde bis vor wenigen Jahren von einer einzigen Vergletscherung, die die externsten Glazialrelikte hinterlassen hätte, abgesehen. Hier hingegen wird von einer solchen Vergletscherung ausgegangen, die gemäß LGRB (2003, 2005), ELLWANGER et al. (2011a), Villinger (2011) als Hosskirch bezeichnet wird. In der Karte der Größten Rheinischen Vergletscherung GRG (Abb. 4) bilden alle äußersten glazialen Zeugen den Eisrand.

Der Außensaum der größten Vorland-Vereisung des Rheingletschers setzt im Westen dort ein, wo seit dem Endabschnitt der Deckenschotter-Eiszeiten die Erosionsbasis des gesamten Rheingletschergebiets lag, an der KlettgauerPforte bei Schaffhausen am Hochrhein (PENCK 1939). Die Peripherie dieser Vergletscherung schwingt sich in weitem Bogen über den Hegau und das oberschwäbische Donautal hinüber ins Illergebiet bis zum Bergland der Adelegg. Seit PENCK \& BRÜCKNER (1909) wurde bis vor kurzem der nordwestliche Randstreifen dieser äussersten Vergletscherung bis zum Bussen ausnahmslos der Riss-Eiszeit zugeordnet. Ab dem Raum Biberach südostwärts bis zur Aitrach und zur Adelegg wurde hingegen postuliert, dass die äußersten Moränen in der Mindel-Eiszeit gebildet worden seien (Abb. 5). Erst Ellwanger (2003) verknüpfte alle äußersten glazialen Bildungen zu einem einzigen Eisrand unter der von ihm eingeführten Bezeichnung MEG.

\subsection{Nordwestliches Rheingletschergebiet}

Angesprochen ist der Geländestreifen von Messkirch bis Riedlingen beidseits der Donau, respektive von der Homburg bis zum Bussen. Detaillierte und auf eine Grosszahl von Bohrungen gestützte Daten aus dem Gebiet von Messkirch finden sich bei Werner (1975, Beil. 8). Er stellt sämtli-

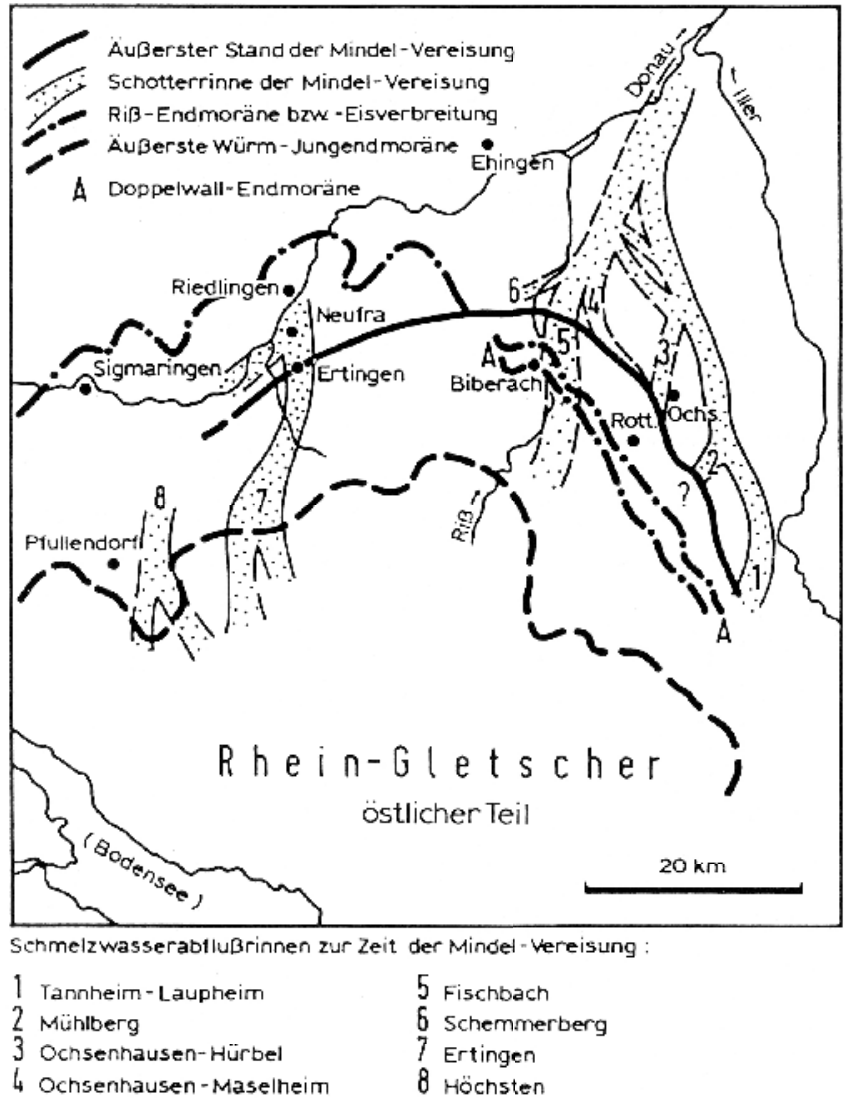

Abb. 5: Nordrand der Mindel- und der Riss-Vergletscherung nach Haag 1982. Beachte die Überkreuzung der Gletscherfronten.

Fig. 5: Northern margin of the Mindel- and the Riss-Glaciation according to Haag 1982. Notice the crossing-over of the glacier frontiers.

che glazialen Bildungen in die Riss-Eiszeit. Hinsichtlich der frühen „risszeitlichen“ Gletscherbewegungen unterscheidet er einen ersten Vorstoß auf so genannte Messkircher Stände und, nach einem Eisrückzug, den Hauptvorstoß zum äußersten Stand bei Vilsingen. Nach einer weiteren Rückzugsphase verbunden mit der Anlage des heutigen Ablachtals sowie der Entstehung des heutigen Donautals kam es zum Vorstoß auf den von ihm definierten Waldbühlstand (Abb. 6). Ausgewiesen durch eine Abfolge von Endmoränenkuppen zwischen Gallmannsweil und Messkirch wird diese Eisrandlage mit dem Biberacher Riss-Doppelwall korreliert (WERNER 1994). Gemäß diesem Szenario soll die bedeutende morphologische Umgestaltung des Donau-Ablach-Systems in einem Interstadial zwischen Zungen-Riss und Doppelwall-Riss sensu SCHREINER (1985, Tab. 6) erfolgt sein.

Auf die Interpretation von Werner (1975) stützen sich die umfassenden Untersuchungen von Villinger (1985, 166174, Abb. 4) zur Fluss- und Landschaftsgeschichte im Raum Sigmaringen-Riedlingen. Zwar wird dort in Abb. 4 ein Mindel-Maximum zwischen Scheer und Kanzach angedeutet, die grossen Ereignisse

- der Donau-Staubildungen

- der Verschüttung der altpleistozänen Donaurinnen,

- der Anlage eines neuen breiten Donaulaufes

bleiben jedoch auch hier der älteren bis jüngeren Riss-Eiszeit zugeordnet.

Die von SCHREINER (1980) detailliert untersuchten Ertinger Schotter (Abb. 8) wurden aufgrund des hangenden Pa- 


\section{Quartärgeologisches Sammelprofil Raum Messkirch}

Nicht massstäblich, horizontal ca. $10 \mathrm{~km}$, stark überhöht, Höhen korrekt

Grundlagen: Werner 1975; Geol. Karte und Erläuterungen Blatt Messkirch 1994

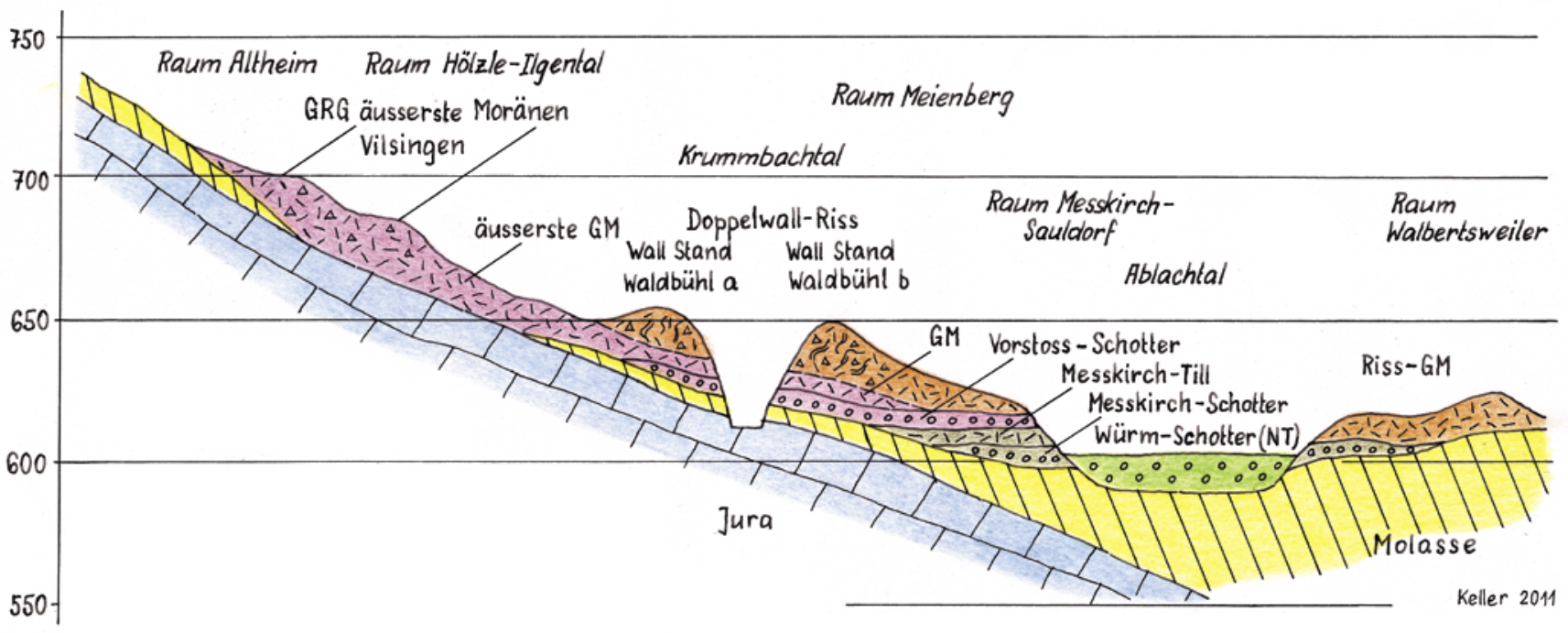

Abb. 6: Quartärgeologisches Sammelprofil der äußersten Randzone im Nordwesten des Rheingletschers bei Messkirch.

Fig. 6: Quaternary geological composite section of the most external margin in the northwest of the Rhine Glacier near Messkirch.

läobodens von Neufra und der abdeckenden Riss-Moräne als älter erkannt und demzufolge als mindelzeitlicher Deckenschotter angesehen. In der paläopedologischen Untersuchung des Bodens von Neufra (BIBUs \& KöSEL 2001) wird als Altersstellung eine mögliche mehrphasige Bildung während mehr als einem Interglazial vor dem Doppelwall-Riss in Betracht gezogen.

Der Schritt zur Erkenntnis, dass im äußersten, glazial überfahrenen Gebiet zwischen Messkirch und Riedlingen eine ältere Eiszeit vorliegt, beruht auf Beobachtungen in zwei Kiesgruben: Krauchenwies/Bittelschiess und Datthausen (EllwANGER et al. 2011a, 404-407). In Krauchenwies findet sich unter mächtigen Abfolgen von Diamikten und Schottern eine Feinsedimentlage, in der pollenanalytisch ein HolsteinInterglazial nachgewiesen wurde (Abb. 12 in Kap. 5.2). An der Lokalität Datthausen stiess eine Bohrung unter einem 45 m mächtigen Stapel alpiner Schotter mit Rissmoränen im Top auf Rheingletscher-Till über Molassefels (Abb. 7). Diese Eiszeit älter als Riss bezeichnet Ellwanger (2003) mit dem Namen MEG.

\section{Diskussion und Interpretation}

Aufgrund der Befunde in den Aufschlüssen Krauchenwies/ Bittelschiess und Datthausen hat die Vergletscherung des GRG, gleichzusetzen mit „Hosskirch“, die älter als Riss einzustufen ist, zwischen Sigmaringen und Riedlingen die Donau überschritten und das äußerste Band glaziärer Ablagerungen hinterlassen (Abb. 4). Südwestlich Sigmaringen ziehen sich die äußersten Glazialrelikte in einem Band von flachen Kuppen hin, die abschnittsweise undeutlich in zwei Reihen angeordnet sind (Abb. 6). Bei der Homburg über der Hegau-Niederung schieben sich markantere, unzweifelhafte Riss-Wälle bis zur Außengrenze der glazialen Bildungen vor. Von hier an bleibt Riss deutlich intern und ist wie bei Biberach zu ei- nem Doppelwallsystem entwickelt, das sich von Honstetten über Gallmannsweil und Messkirch bis gegen Krauchenwies als Waldbühl-Eisrandlage (WERNER 1975, 1994) verfolgen lässt (Abb. 6). Zwischen Mengen und Datthausen sind keine morphologischen Anhaltspunkte für eine Riss-Randlage auszumachen.

Von diesen Erkenntnissen ausgehend würden die von VILlinger (1985) der Riss-Eiszeit zugeschriebenen Verschüttungen, Staubildungen und Laufverlegungen der Donau im Raum Sigmaringen-Riedlingen in die Zeit des GRG fallen.

Das Profil des Ertinger Schotterbandes (SCHREINER 1980) kann zwanglos bis Datthausen verlängert werden, womit dort die liegenden Schotter dem Ertinger Schotter zuzuordnen wären (Abb. 8). Das Paket der hangenden Schotter würde damit als Vorstoß-Schotter der Riss-Eiszeit zu deuten sein, wobei die auflagernde Moräne durch den Rissgletscher abgelagert worden wäre. Der basale Diamikt in der Bohrung von Datthausen (Abb. 7) dürfte gemäß seiner nördlichen Lage dem GRG = Hosskirch angehören, was auch ELLWANGER et al. (2011a) annehmen. Dies legt nahe, dass der Ertinger Schotter im Größten Rheinischen Glazial beim etappenweisen Rückschmelzen abgelagert wurde.

Diese Vorstellung kann durch die den Strang der Ertinger Schotter kreuzende Mottschiesser Rinne untermauert werden. Diese verläuft in SW-NE-Richtung von Pfullendorf Richtung Federsee und folgt einer Molasse-Störung. Sie weist ein geringes Gefälle von ca. $1 \%$ auf, was aus GK 25, Blatt 8021, Pfullendorf hervorgeht (VILLINGER 2003). Es ergibt sich, dass das S-N verlaufende Ertinger Schotterband westlich Saulgau von der Mottschiesser Rinne, die jüngere Deckenschotter führt, gekreuzt wird. Ihre Rinnenbasis liegt östlich Pfullendorf auf $630 \mathrm{~m}$ ü. M., womit sie den Ertinger Schotter auf rund 615 m queren dürfte. Das Top der Ertinger Schotter reicht knapp bis auf dieses Niveau, die Schotterbasis 
befindet sich auf ca. $590 \mathrm{~m}$ (Abb. 8). Daraus darf geschlossen werden, dass der Ertinger Schotter nicht mit den Deckenschottern der Mottschiesser Rinne zu verbinden ist, sondern eine jüngere Schüttung darstellt, wofür das GRG in Frage kommt.

Im Weiteren verläuft das nach Süden als Extrapolation verlängerte Band der Ertinger Schotter um $50 \mathrm{~m}$ tiefer als der jüngere Deckenschotter von Königseggwald (Abb. 8). Demzufolge wären die Ertinger Schotter keine Deckenschotter, sie müssen jünger sein als diese, aber älter als Riss, was ihre Zuordnung zum GRG annehmen lässt.

In der Nordschweiz wird die größte Vergletscherung als Möhlin-Glazial bezeichnet (GrAf 2009a, Keller \& Krayss 2010, Preusser et al. 2011) und vor dem Holstein-Interglazial positioniert. Diese Eiszeit entspricht gemäß ihrer räumlichen Ausbreitung dem Größten Rheinischen Glazial im hier diskutierten nordwestlichen Gebiet des Rheingletschers. Aufgrund des Nachweises des Holstein-Interglazials in der Sedimentabfolge von Bittelschiess steht einer Gleichsetzung Möhlin $=$ Hosskirch $=$ Größtes Rheinisches Glazial $(\mathrm{GRG})$ nichts im Wege.

\subsection{Zur Bildung der tiefen Becken}

Die frühpleistozänen Deckenschotter des westlichen Bodenseeraums sind durch eine Periode erhöhter Eintiefung von den mittel- und spätpleistozänen Ablagerungen getrennt (Schreiner 1974, 1992; Graf 1993, 2009b; Keller \& Krayss 1999, 2010). Neben Absenkungen im Oberrheingraben spielte die Umlenkung des Alpenrheins von der Donau zum Oberrhein die Hauptrolle, die im Anschluss an die Zeit der Tieferen Deckenschotter erfolgte (KELLER 2009). Sie brachte dem Hochrhein ab der Aare-Mündung nahezu die doppelte Wassermenge und damit verstärkte Erosionskraft. Für das Flusssystem des Alpenrheins bis zur Aare setzte eine äußerst intensive fluviale Ausräumung des Bodensee-Hochlandes mit dem Resultat einer tiefen Durchtalung ein.

Waren die Gletscher der Deckenschotter-Eiszeiten im Bodensee-Vorland noch auf das hoch liegende, frühpleistozäne danubische Entwässerungsnetz ausgerichtet, so folgten nun die mittelpleistozänen Eisströme den vorgezeichneten tiefen Flusstälern. Durch subglaziale Erosion verbreiterten sie die Talzüge und schürften übertiefte Becken und Tröge aus, weshalb diese Glaziale im Rhein- und Aareraum als Becken-Eiszeiten bezeichnet werden (Keller \& Krayss 1999; Preusser et al. 2011).

Häufig findet sich in den tiefen Becken über dem Felsboden Moräne. In den hangenden, warmzeitlichen Sedimenten konnte mehrfach das Holstein-Interglazial direkt nachgewiesen oder zumindest wahrscheinlich gemacht werden. Alpennah betrifft dies beispielsweise das Aaretal südöstlich Bern mit dem Thalgut (Schlüchter 1989; Welten 1982) oder das Linthbecken mit dem Günterstall-Delta (JEANNET 1923; Schindler 2004; Keller \& Krayss 2010). Alpenfern bildet das Singener Becken den westlichsten Teil des Bodenseebeckens. Die dem Felsgrund aufsitzenden Diamikte gehören ebenfalls der größten Vergletscherung an (SzENKLER \& Bock 1999), indem typische Pollen für Samerberg-Holstein nachgewiesen wurden. Die Becken selbst müssen daher vorwiegend in der ersten und grössten Becken-Eiszeit, dem

\section{Kiesgrube Maucher bei Datthausen Aufschlussprofil und Bohrprofil}

\author{
Grundlagen: Ellwanger et al. 2011 a
}

müM Feldaufnahmen Keller und Krayss

Abb. 7: Quartärgeologisches Profil Datthausen (Kiesgrube und Bohrung) im äußersten Norden des Rheingletschergebietes. Auswertung siehe Tabelle.

Fig. 7: Quaternary geological section of Datthausen (gravel pit and drilling) in the most northern part of the Rhine Glacier. Analysis see table.

Größten Rheinischen Glazial GRG = Möhlin = Hosskirch, ausgeschürft worden sein.

Auch die an die Hauptbecken nach außen ins weitere Vorland vorgeschobenen Neben- und Zweigbecken sind überwiegend im Größten Rheinischen Glazial von den von den Eiskörpern der Hauptbecken ausstrahlenden Gletscherzungen ausgeschürft worden. Belegt wird dies in den Becken von Hosskirch oder Wattenweiler durch Funde von Pollen, die auf das Holstein-Interglazial schliessen lassen (ELLWANGER et al. 1995; Bludau in Ellwanger et al. 1999).

\subsection{Raum Risstal [Biberach] - Aitrachtal}

Ab Biberach galt bisher für den äußersten Eisrand das Konzept von PENCK \& BRÜCKNER (1909), das diesen Mindel zuwies. Der Geländestreifen dieser größten Vergletscherung 


\begin{tabular}{|c|c|c|c|c|}
\hline & \multicolumn{4}{|c|}{ Auswertung Profil Datthausen [Abb. 7] } \\
\hline & Lithologie & Genetische Interpretation & $\begin{array}{l}\text { Glazialchronologie gemäß } \\
\text { ELLWANGER et al. 2011a }\end{array}$ & $\begin{array}{l}\text { Glazialchronologie } \\
\text { gemäß Autor }\end{array}$ \\
\hline 1 & $\begin{array}{l}\text { Verwitterungszone } \\
\text { Bodenbildung }\end{array}$ & $\begin{array}{l}\text { Ältere Verwitterung und } \\
\text { Paläoboden, bis } 3 \text { m mächtig }\end{array}$ & & $\begin{array}{l}\text { Eem-Interglazial und } \\
\text { rezenter Boden }\end{array}$ \\
\hline 2 & $\begin{array}{l}\text { Moräne Rheingletscher, } \\
\text { im E zweigeteilt }\end{array}$ & $\begin{array}{l}\text { Eisüberfahrung, Gletscher-Vorstoß } \\
\text { mit Oszillation }\end{array}$ & $\begin{array}{l}\text { Riss-Eiszeit, Maximalvorstoß } \\
\text { Außenwall-Riss }\end{array}$ & $\begin{array}{l}\text { Riss-Glazial, Maximalvorstoß } \\
\text { bis Datthausen }\end{array}$ \\
\hline 3 & siltig-tonige Feinsedimente & lokale Stausedimente & & Tümpel vor der Riss-Eisfront \\
\hline 4 & $\begin{array}{l}\text { Kies mit alpinem Material, } \\
\text { teils verkittet }\end{array}$ & $\begin{array}{l}\text { Vorstoß-Schotter, örtlich durch } \\
\text { Kalkkrusten verfestigt }\end{array}$ & $\begin{array}{l}\text { Riss-Eiszeit, } \\
\text { Hochterrassenschotter }\end{array}$ & $\begin{array}{l}\text { Riss-Gletschervormarsch, } \\
\text { Vorstoß-Schotter }\end{array}$ \\
\hline 5 & $\begin{array}{l}\text { Grobblock-Horizont aus } \\
\text { Oberjura \& Tertiär, } \\
\text { kiesreiche Matrix }\end{array}$ & $\begin{array}{l}\text { Katastrophen-Ereignis: } \\
\text { Bergsturz und See-Ausbruch? } \\
\text { Flutwelle aus der Alb }\end{array}$ & Prä-Riss? & $\begin{array}{l}\text { Prä-Riss, interglaziales } \\
\text { Ereignis oder während } \\
\text { Habsburg-Glazial? }\end{array}$ \\
\hline 6 & $\begin{array}{l}\text { Kiese mit alpinen Geröllen, } \\
\text { Entkalkung }\end{array}$ & $\begin{array}{l}\text { Entkalkung: Hinweis auf } \\
\text { Sedimentationspause }\end{array}$ & & $\begin{array}{l}\text { Interglazial? Entkalkung als Unter- } \\
\text { bruch in der Ablagerung }\end{array}$ \\
\hline 7 & $\begin{array}{l}\text { verkittete Kiese, alpin } \\
\text { zurückschmelzenden }\end{array}$ & Schotter eines etappenweise & $\begin{array}{l}\text { Riss-Hochterrasse oder älter } \\
\text { in Etappen während }\end{array}$ & GRG Mindel-Schotter, Schüttung \\
\hline 8 & Kiese mit alpinem Material & Gletschers & & dem Abschmelzen \\
\hline 9 & $\begin{array}{l}\text { Grobkiese mit Alpin } \\
\text { und Oberjura }\end{array}$ & $\begin{array}{l}\text { Begrenzte Wiedervorstöße } \\
\text { angezeigt durch Grobmaterial }\end{array}$ & & \\
\hline 10 & $\begin{array}{l}\text { Till Rheingletscher } \\
\text { mindestens Datthausen }\end{array}$ & $\begin{array}{l}\text { Gletschervorstoß bis } \\
\text { oder Älteres Riss }\end{array}$ & $\begin{array}{l}\text { Hosskirch-Vorstoß? } \\
\text { äußerste Glazialgrenze }\end{array}$ & GRG: Gletscher-Vorstoß bis \\
\hline 11 & Untere Süßwassermolasse & & & GRG Mindel-Glazialwanne \\
\hline
\end{tabular}

ist dadurch gekennzeichnet, dass er intern durch den äußeren Moränenwall des Doppelwall-Riss und das Zungenriss morphologisch eindeutig überfahren ist (SCHREINER \& EBEL 1981; HAAg 1982 Abb. 10). Als bedeutende Typuslokalität innerhalb des Mindel-Geländestreifens gelten die zum Illertal gerichteten Querprofile von Hauerz und Seibranz (SCHreINER 1996, Fig. 2-5). Hier demonstrierten SCHrEINER \& EBEL (1981) die Einführung der Haslach-Eiszeit, einer im Penck'schen System neuen Eiszeit zwischen Günz und Mindel. In der Bohrung von Unterpfauzenwald belegt eine pollenanalytisch gesicherte Interglazialschicht (GöTTLICH \& WERNER 1974) ein älteres Interglazial als Holstein (BLUdAU gemäss ScHrEINER 1992). Sie trennt die Mindelmoräne im Hangenden von der Haslachmoräne im Liegenden. Dieses Interglazial dürfte dem Cromer Komplex angehören (BIBus et al. 1996). Unter dieser finden sich nach einer Erosionsdiskordanz und einem Paläoboden Schotter, die als Zeiler Schotter (= Günz) angesprochen werden. Daraus ergab sich die Eiszeitenabfolge Günz - Haslach - Mindel - Riss, wobei Günz als Ältere, Haslach und Mindel als Jüngere Deckenschotter verstanden werden.

Zur Entwässerung des Mindel-Glazials im nordöstlichen Rheingletschergebiet liegt die fundierte Untersuchung von HAAG (1982) vor. In seiner Abb. 1 lassen sich zwei Typen von Schottersträngen erkennen. Ein System (1) verweist offensichtlich auf die Eisrandentwässerung während dem Maximalstand der Mindel-Vergletscherung. Schotterstränge des Typs (2) hingegen haben ihren Ursprung am Südrand des oberschwäbischen Plateaus und beziehen sich somit auf in- terne Stände der Vergletscherung. Dem Höchststand entsprechen (1) die Schemmerhofer Schotter, der Ochsenhausen-Maselheimer und -Hürbeler Schotter sowie sehr ausgeprägt der Tannheim-Laupheimer Schotter. Zum Typ (2) gehören der Fischbachschotter sowie der Mühlberger Schotter. Von allen diesen Abflussbahnen finden sich bei HAAG (1982, Abb. 4) detaillierte Längsprofile. Speziell auf den Typ (2) verweisen die Ertinger Schotter (SchreINER 1980), die sich aus dem Raum Saulgau-Hosskirch bis zur Donau bei Datthausen erstrecken (Abb. 8 in Kap. 4.1).

Über die Verhältnisse im oberen Aitrachtal gibt die GK Leutkirch-Ost (WENNINGER 1994, Abb.1) einen guten Einblick. Offensichtlich reichte die Mindel-Vergletscherung als ansgedehnteste Vereisung bis Altmannshofen und südlich bis auf die Linie der heutigen Hofser Ach, wo sie auf die Ausläufer des Adelegg-Berglandes stieß. Demnach lag bei Altmannshofen auch das Gletschertor, an dem die TannheimLaupheimer Schotter ihren Ursprung hatten (Abb. 9).

\section{Diskussion und Interpretation}

Im Raum Risstal-Aitrachtal ist gemäß den dargelegten Befunden die größte Vergletscherung mit den äußersten Glazialzeugen älter als Riss. Im Nordosten des Rheingletschergebiets sowie im Nordwesten ist aufgrund der bisherigen Erkenntnisse und Darlegungen nur eine einzige Vergletscherung ausgedehnter als Riss nachweisbar. Für den Nordwesten konnte glaubhaft gemacht werden (Kap. 4.1), daß es sich dabei um das Größte Rheinische Glazial GRG = Hosskirch handelt, das sich vor Riss, aber nachfolgend zu den Decken- 


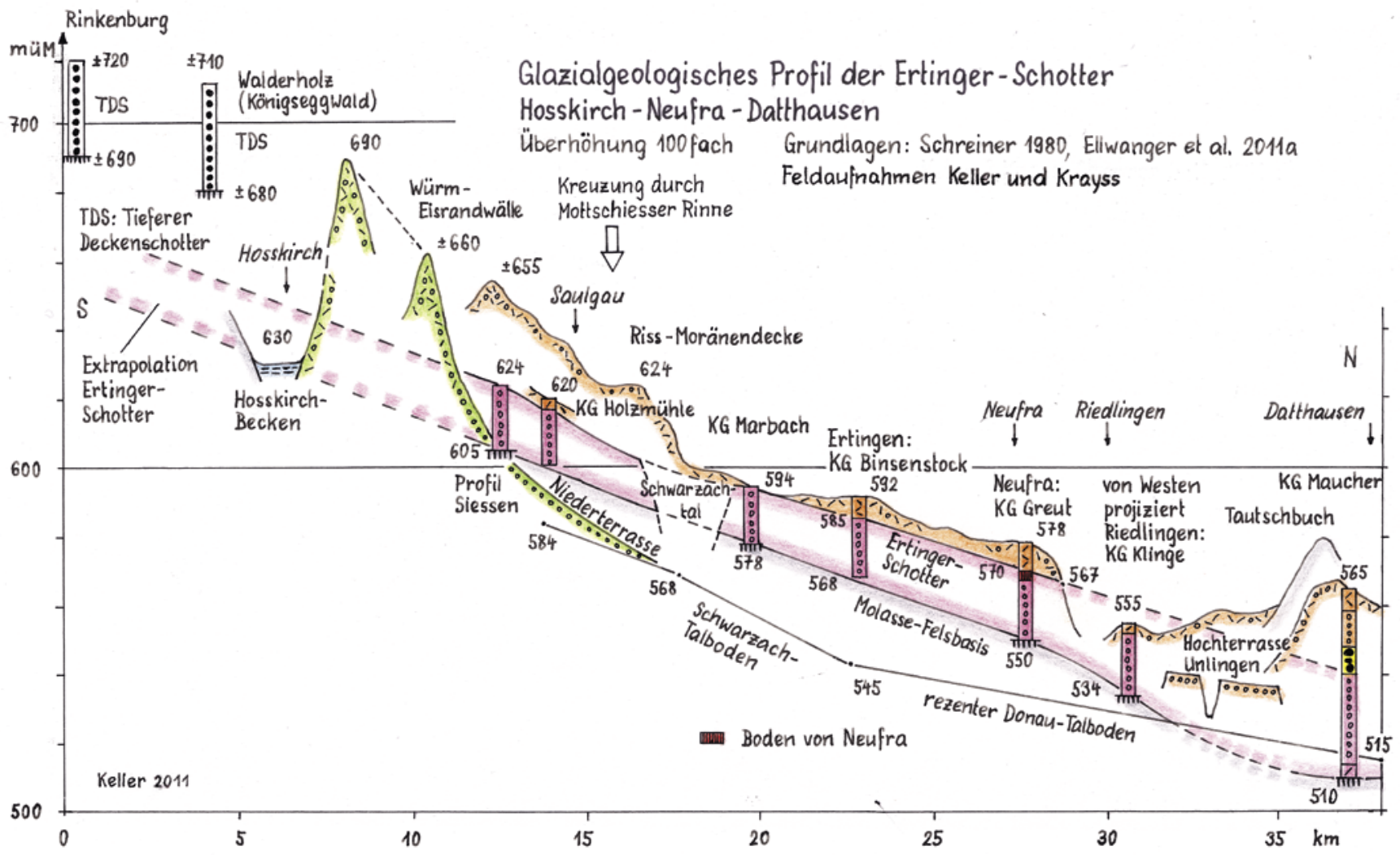

Abb. 8: Glazialgeologisches Längsprofil der Ertinger Schotter zwischen Hosskirch und Datthausen (nördlicher Rheingletscher), ergänzt nach Schreiner 1980. Fig. 8: Glacial geological longitudinal profile of the Ertinger gravel between Hosskirch and Datthausen (northern Rhine Glacier), completed after Schreiner 1980.

schottern einschiebt. Falls diese Befunde akzeptiert werden, ergeben sich daraus für den Nordosten des Rheingletschers schwerwiegende Konsequenzen:

1. Es muss wohl davon ausgegangen werden, dass auch im Nordosten die äussersten Vergletscherungszeugen dem GRG $=$ Hosskirch angehören. Sie wurden bisher Mindel zugewiesen, das damit hier zum GRG wird.

2. Schreiner \& Ebel (1981) sowie HAAg (1982) konnten zeigen, dass der Hauptstrang der Entwässerung, der Tannheim-Laupheimer-Schotter im Süden im Aitrachtal mit Moräne verzahnt ist, was die Schotter als Mindel-Schüttungen ausweist. Wenn die Mindel-Moränenwälle dem GRG zugeordnet werden, so ist daraus zu schließen, dass die zugehörigen bisherigen Mindel-Schotterstränge zu GRG-Sandern werden.

3. Da das GRG eine Becken-Eiszeit ist (Kap. 4.2), die nachfolgend nach den Deckenschottern einzustufen ist, so muss hier im Nordosten Mindel zur Becken-Eiszeit werden, womit es jünger wäre als die Deckenschotter.

4. Die bisherigen Mindel-Schotterstränge im Nordosten des Rheingletschers würden zu Schüttungen des GRG. Sie wären damit keine Deckenschotter, da diese ihrerseits älter sind als die Becken-Eiszeiten. Die jüngeren Deckenschotter würden sich somit auf Haslach beschränken.

Welche Folgen sich aus diesen Interpretationen für den östlich anschliessenden Illergletscher ergeben würden, kann in diesem Zusammenhang nicht abgeschätzt werden.

\subsection{Ausmasse der Vorlandvergletscherung}

Für den Versuch der paläoglazialen, kartographischen Re- konstruktion des Vorlandgletschers im Größten Rheinischen Glazial GRG (Abb. 4) wurden Eisrandmarken am Außensaum des Gletschers und höchste glaziale Spuren in den Voralpen verwendet. Die alpenwärtige Begrenzung des Vorlandgletschers ist festgelegt durch die dem tektonischen Alpenrand vorgelagerten hohen Molasse-Berge, die das Eisstromnetz noch überragten. Im Rheintal ist das Alpentor von Oberriet-Koblach massgebend. Das Isohypsenbild beruht auf diesen Marken sowie auf Analogieschlüssen zum Rhein-Linth-Gletscher während der Würm-Eiszeit (KeLLER \& KrAYss 1982, 1993, 2005). Für die Vorlandvergletscherung des GRG ergibt sich ein plausibles Bild, das den Eisflussrichtungen aus den Alpen heraus und der Geometrie des Eiskörpers gerecht wird.

Methodisch standen als Grundlage die Berechnungen und Abschätzungen zur Würm-Vergletscherung zur Verfügung (Keller \& Krayss 1993), die von Benz (2003) durch digitale Datenerfassung und Modellierung im GIS bestätigt worden sind. Für die Volumenberechnung wurden für 260 Punkte in einem $5 \times 5 \mathrm{~km}^{2}$ Raster die Höhendifferenzen zum Eiskörper des Würm-Maximums bestimmt. Bei Rasterpunkten, die in ein dem GRG zugewiesenes Becken fielen, wurden die Höhen des Felsbodens für die Volumenberechnung mit einbezogen, dies unter der Annahme, dass die Beckenausräumung sich im Wesentlichen im GRG abgespielt hat (Kap. 4.2). Die über den Würm-Eisrand hinaus reichenden Areale wurden mit einem Flächenraster von 2,5 x 2,5 km² ausplanimetriert. Zusätzlich musste das Eisvolumen ausserhalb der WürmGrenze bestimmt werden.

Auf diesen Grundlagen basierend konnten Fläche und Volumen des Vorlandgletschers bestimmt werden. Resultate: 


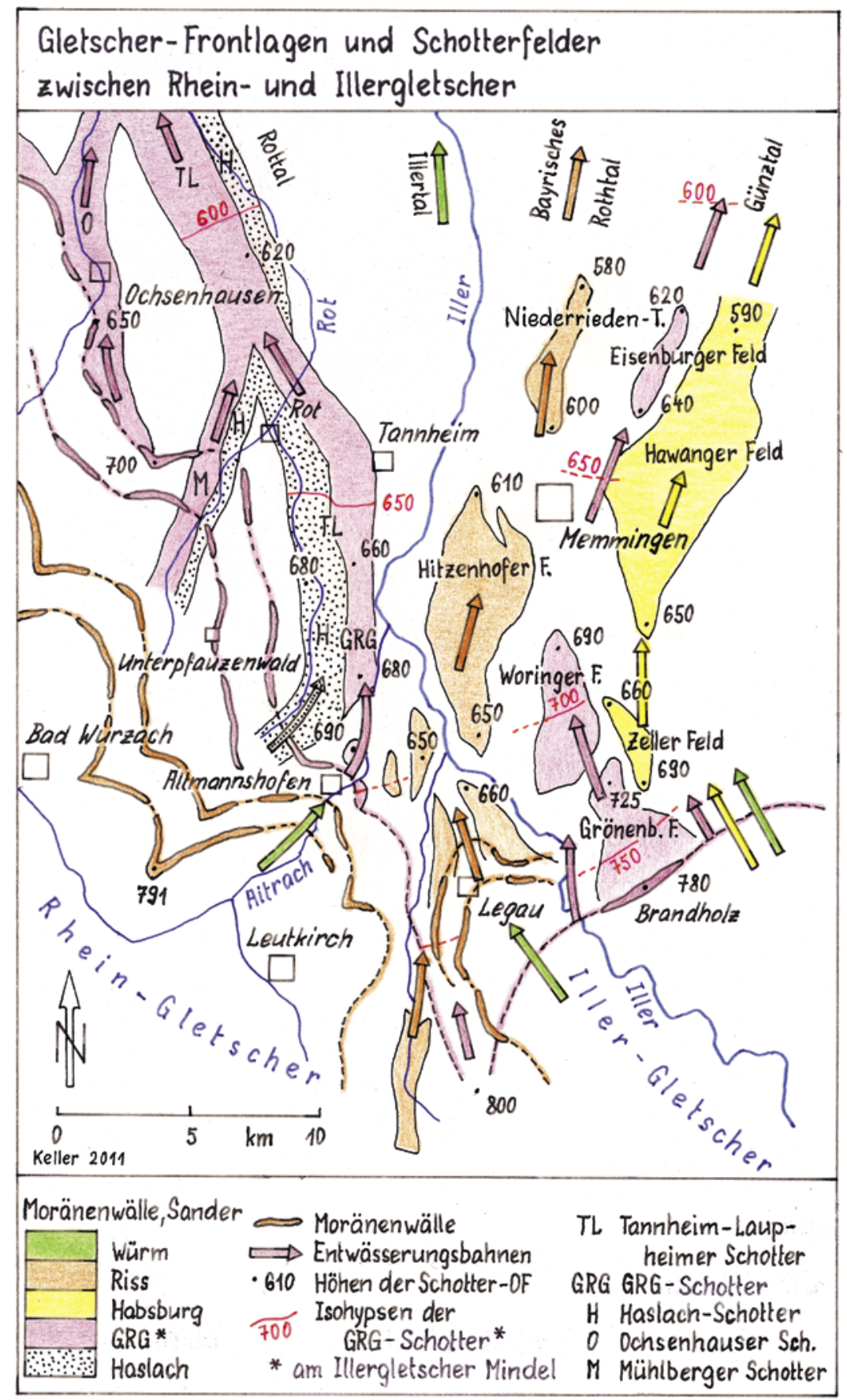

Abb. 9: Gletscherfronten, Sander und Entwässerung zwischen dem nordöstlichen Rheingletscher und dem Illergletscher.

Fig. 9: Frontiers of glaciers, outwash plains and drainage between the northeastern Rhine Glacier and the Iller Glacier.

Vorlandvergletscherung des Größten Rheinischen Glazials $=$ Hosskirch

Vergletschertes Areal $9000 \mathrm{~km}^{2}$ (125\% zu Würm)

Volumen des Eiskörpers $3300 \mathrm{~km}^{3}$ (137\% zu Würm) Mittlere Eismächtigkeit $370 \mathrm{~m}$
Zum Vergleich die Vorlandvergletscherung des Würm-Maximums

$7200 \mathrm{~km}^{2}$

$2400 \mathrm{~km}^{3}$

$335 \mathrm{~m}$

\section{Modell eines Habsburg-Glazials}

Für die Nordschweiz konnte plausibel gezeigt werden, dass sich zwischen das Größte Rheinische Glazial (GRG) = Möhlin und die Riss-Eiszeit = Beringen eine Vorlandvergletscherung einschiebt, die in etwa die Ausmaße der Würm-Vergletsche- rung erreichte und von deren Frontpositionen aus Schmelzwasserströme die Hochterrassen schütteten. Diese als Habsburg-Glazial bezeichnete drittletzte Eiszeit ist in den übertieften Becken in den Sedimentstapeln mehrfach zu erkennen (Graf 2009a, Keller \& Krayss 2010, Preusser et al. 2011).

Damit stellt sich die Frage, ob nicht auch im übertieften Bodenseebecken und in seinen Randgebieten das HabsburgGlazial erkennbar ist. In diesem Sinne wird eine Modellvorstellung entwickelt und anschließend versucht, Indizien, die für dieses Glazial sprechen, beizubringen.

\subsection{Ausdehnung und Entwässerung}

In der Karte der Abb. 10 sind zu Vergleichszwecken die in der Nordschweiz anhand der Ansatzstellen der Hochterrassen rekonstruierten Zungenlagen der Habsburg-Vergletscherung (Keller \& Krayss 2010) für den Reuss- und den Linthglet- 


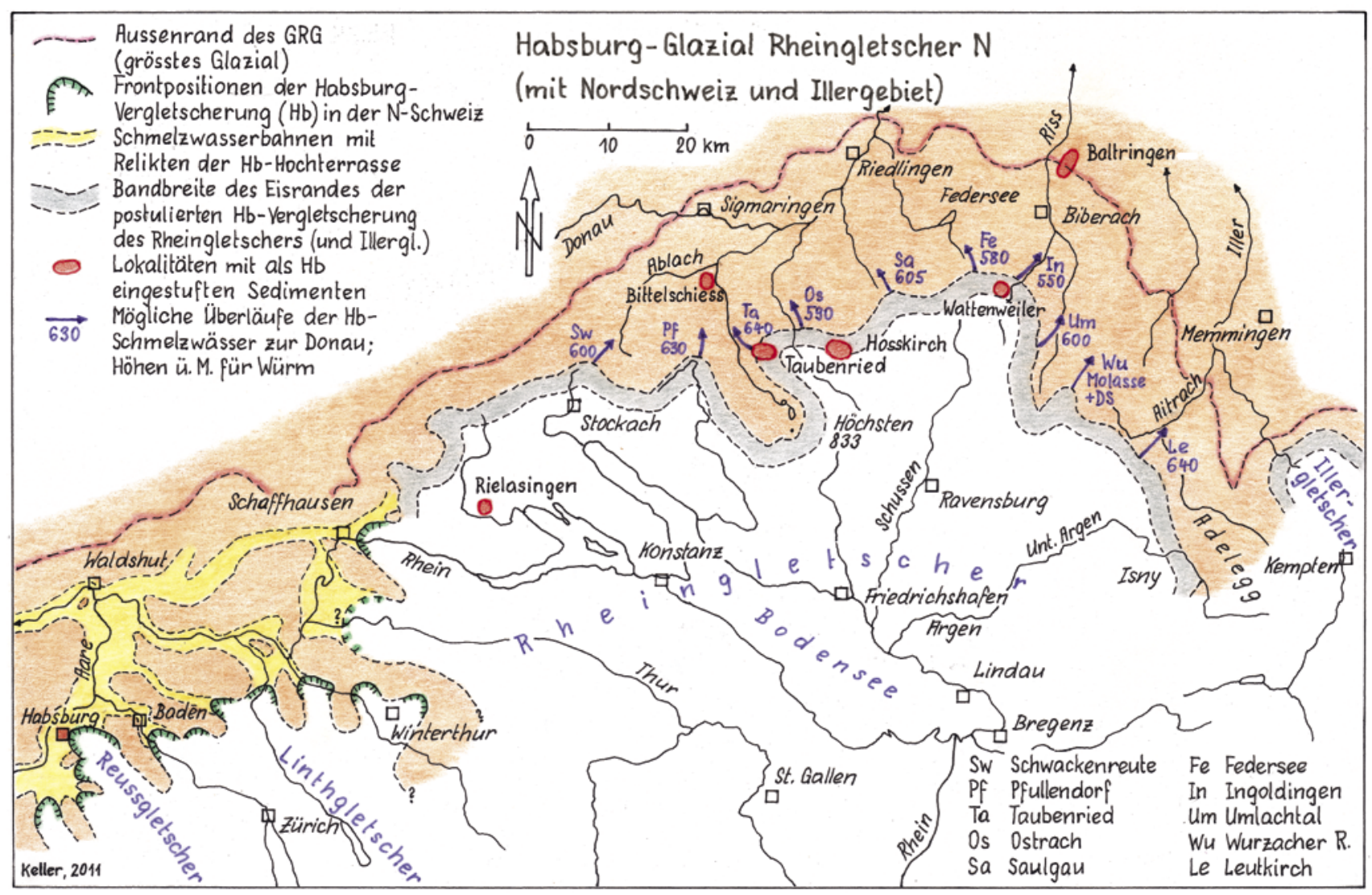

Abb. 10: Geschätzte Eisausdehnung der postulierten Habsburg-Vergletscherung.

Fig. 10: Estimated ice extension of the postulated Habsburg glaciation.

scher, bei Schaffhausen auch für den westlichen Rheingletscher, eingetragen. In Erkenntnis, dass dieses Frontenbild sehr gut mit der Würm-Vergletscherung vergleichbar ist, ist im nördlichen Rheingletschergebiet modellmäßig und basierend auf der Würmausdehnung ein Bandstreifen eingezeichnet, in dem allenfalls Indizien für eine Habsburg-Vergletscherung zu erwarten sind. Beim Illergletscher ist in der Karte Abb. 10 ebenfalls das für eine Habsburg-Vergletscherung in Frage kommende Band für den Frontbereich dargestellt.

Im Gegensatz zur Nordschweiz, wo die Entwässerung nach Westen vorgegeben ist, müssen beim nördlichen Rheingletscher die Eisfronten die Wasserscheide zur Donau mindestens erreichen, damit Schmelzwässer nach Norden abfließen können. Dabei ist auch zu bedenken, dass in einem Glazial dieser Ausdehnung nur während den Hochständen Richtung Donau Schotter durch Schmelzwasserströme abgelagert werden können. Die für eine Habsburg-Vergletscherung in Frage kommenden Überlaufschwellen sind in der Abb. 10 eingefügt.

Die nach Norden gerichteten Überläufe der würmeiszeitlichen Vergletscherung wurden, ausgenommen Ostrach und Riss bei Ingoldingen, nur im Würm-Maximum als der Donau zustrebende Entwässerungswege benutzt. Es sind in der Anlage ältere Rinnen, die vermutlich zum Teil schon im GRG funktionierten. Die in der Karte der Abb. 10 eingetragenen Schwellenhöhen sind würmzeitlich und dürften im GRG noch um Einiges höher gelegen haben, wie es das Südende der Ertinger Schotter nahe legt (Abb. 8).

Im Osten existiert auch noch heute aus dem Bodenseebecken heraus nur der Überlauf der Aitrach zur Iller, der während der Würm-Eiszeit aktiv war. Hoch liegende risszeitliche Moränenwälle nördlich und südlich der Aitrach bei Altmannshofen deuten an, dass der Abfluss zur Iller risszeitlich noch hoch lag und erst würmzeitlich tief ausgestaltet worden ist. Somit steht diese Schmelzwasserbahn für ein allfälliges Habsburg-Glazial außer Betracht.

Im mit $150 \mathrm{~m}$ sehr tiefen Wurzacher Becken, das sich weit nach Nordosten erstreckt, sind in den Beckensedimenten Würm und Riss nachgewiesen GRÜGER \& SCHREINER (1993). Es dürfte daher im Zuge älterer Glaziale ausgeschürft worden sein. Es scheidet aber, da nordöstlich anschließend Höhenrücken mit Deckenschottern vorhanden sind, als Entwässerungsweg für eine angenommene Habsburg-Vergletscherung zum Vorneherein aus.

Ausgehend vom Austritt der Unteren Argen aus dem Adelegg-Bergland kann eine hypothetische Randentwässerung der Habsburg-Vergletscherung entlang dem Band des Modells (Abb. 10) angenommen werden. Sie setzt in dem in Molasse angelegten Tal der Unteren Argen an, das einen flachen Talboden mit geringer Lockermaterialbedeckung bei $4 \%$ Gefälle aufweist. Bis zum Riss-Überlauf bei Ingoldingen beträgt das Gefälle 3,5\%. Die Fortsetzung Risstalabwärts zum Niveau der Baltringer Hochterrasse reduziert sich auf $2,5 \%$. Werte dieser Größenordnung weisen auch würmzeitlich gesicherte Täler auf. Dieses Randsystem ist so ausgeprägt, dass es zeitlich weiter als Würm in die älteren BeckenEiszeiten zurückreichen dürfte, dabei aber noch etwas höher gelegen hätte.

Aus dem Modell abgeleitet kann zusammenfassend für eine angenommene Habsburg-Eiszeit höchstens mit sechs 


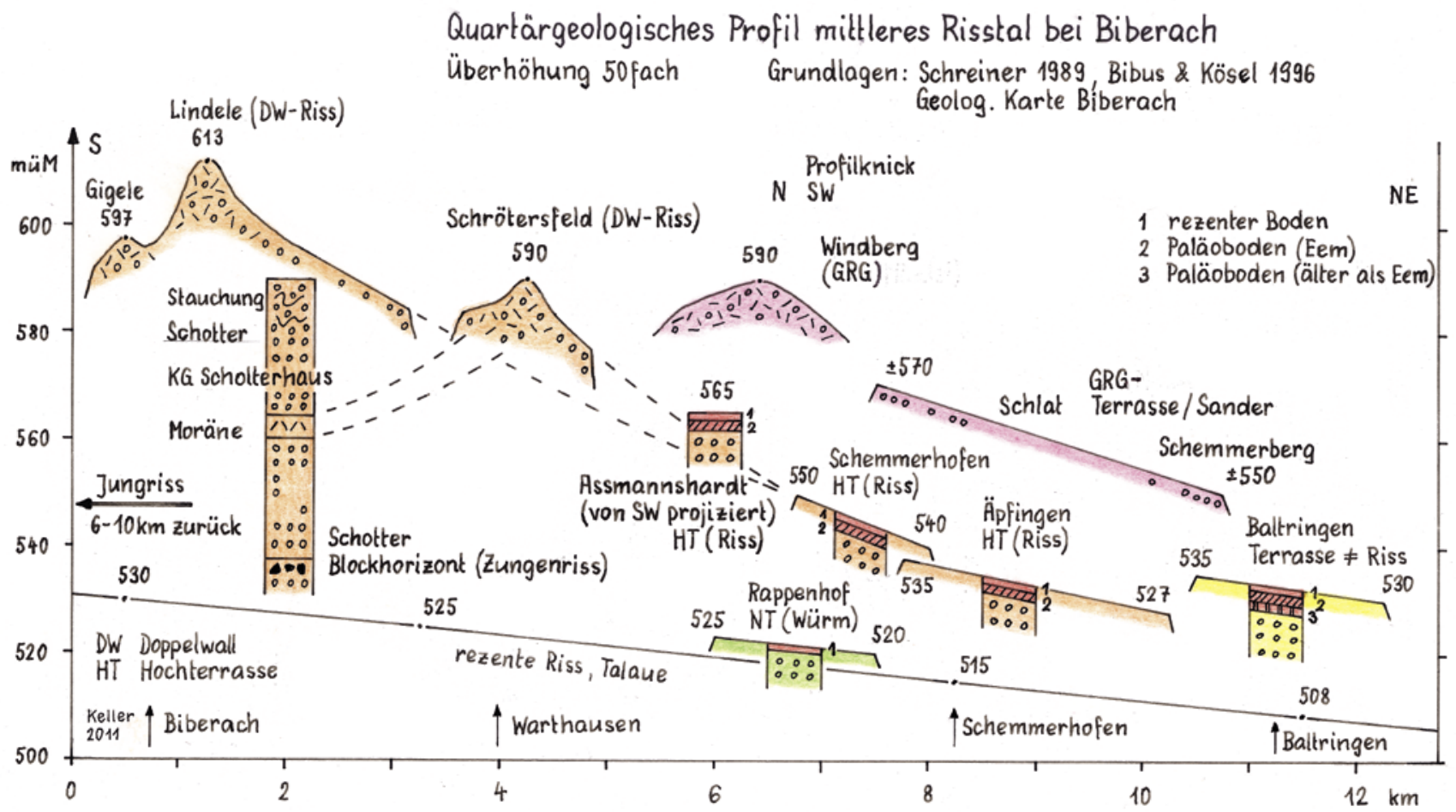

Abb. 11: Profil durch die Frontpositionen der GRG- und der Riss-Vergletscherung im Zusammenhang mit den Sanderresten im Raum Biberach (teilweise nach SCHREINER 1989).

Fig. 11: Longitudinal profile through the front positions of the GRG-and the Riss-glaciation in context with the relics of outwash plains in the region of Biberach (partly after SCHREINER 1989).

möglichen Schmelzwasser-Überläufen, alle zur Donau nach Norden ausgerichtet, gerechnet werden (Abb. 10).

\subsection{Mögliche Relikte im Donau-wärtigen Bereich}

Um einer vorerst modellmäßig postulierten Habsburg-Eiszeit auf die Spur zu kommen, sind einerseits periglazial mögliche Aufschotterungen und/oder Terrassenrelikte zu diskutieren. Anderseits muss intraglazial im beckenseitigen Randbereich der anzunehmenden Habsburg-Vergletscherung (Bandstreifen in Abb. 10) oder im Inneren des Bodenseebeckens nach Indizien gesucht werden. In diesem Sinne wurde versucht die zur Verfügung stehenden quartärgeologischen Profile, bearbeiteten Aufschlüsse und Bohrungen zusammen mit den vorhandenen Bodenbestimmungen und Pollenanalysen neu zu interpretieren. Dabei ist festzuhalten, dass die bisherigen sorgfältigen Bearbeitungen als Grundlage verwendet und als solche in keiner Weise angezweifelt werden.

\section{Risstal-Biberach}

Seit Penck (Penck \& BRÜCKNER 1909) werden die Frontmoränen bei und südöstlich von Biberach mit der Hochterrasse verknüpft und gelten als Riss-Glazial. Im Gebiet Biberach im Norden und der Aitrach im Süden sind drei Riss-Eisrandlagen gefunden worden (SCHREINER \& HAAG 1982, SCHREINER 1985, 1989). Detaillierte Untersuchungen haben SCHREINER (1992) zur Unterscheidung von Zungenriss, Doppelwall-Riss und Jungriss veranlasst, die er durch Interstadiale voneinander abgetrennt hat. In seiner späteren Publikation (ScHreINER 1996) bleibt offen, ob es sich eventuell um Interglaziale handeln könnte, die aber nicht belegt sind. Stratigraphisch wird dem Zungenriss (Älteres Riss) keine Terrasse zugeord- net, dem Doppelwall-Riss (Mittleres Riss) die obere Hochterrasse: Assmannshardt, Schemmerhofen, Baltringen, dem Jungriss die Untere Hochterrasse: Äpfingen oder 13 m-Terrasse (Abb. 11). Im Gegensatz dazu wurden früher (PENCK \& BRÜCKNER 1909) die Frontmoränen des Doppelwall-Riss mit der Unteren Hochterrasse von Äpfingen verknüpft.

Paläopedologische Forschungen (BIBUs \& KöSEL 1996, 2001) erbrachten auf der 13 m-Terrasse von Äpfingen (Untere Hochterrasse) einen warmzeitlichen Paläoboden, weshalb die Schotter der vorletzten Eiszeit, dem als eigenständiges Glazial betrachteten Jungriss, zugewiesen wurden. Hingegen wird die Baltringer Terrasse mit zwei Paläoböden als Obere Hochterrasse ins Doppelwall-Riss gestellt, das daher durch ein Interglazial vom Jungriss zu unterscheiden wäre. Miara (MiArA et al. 1996) fand auf der Baltringer Terrasse einen Horizont mit intensiver Kiesverwitterung und davon getrennt auch einen fossilen Boden. Dementsprechend nimmt er für die Schüttung der Terrasse die drittletzte Eiszeit an.

\section{Diskussion und Interpretation}

Die paläopedologischen Untersuchungen von BIBUS \& KöSEL (1996) ergaben für die Deckschichten und Bodenbildungen zwischen der Unteren Hochterrasse von Äpfingen und den Oberen Hochterrassen von Assmannshardt und Schemmerhofen keine Unterschiede, sodass anzunehmen ist, dass alle derselben Eiszeit angehören. Gemäß der Höhenlage können auch morphostratigraphisch alle drei Terrassen als Hochterrassen dem Doppelwall-Riss zugeordnet werden (Abb. 11). Demnach dürfte die Terrasse von Äpfingen nicht mehr mit dem Jungriss zu verknüpfen sein. Dabei wird davon ausgegangen, dass Jungriss keine eigenständige Vergletscherung darstellt. Dieses bekundet wohl eine interne, stadiale 
Quartärgeologisches Sammelprofil der Kiesgrube Bittelschiess/Krauchenwies südlich Sigmaringen nicht massstäblich Grundlage Bibus \& Kösel 1996

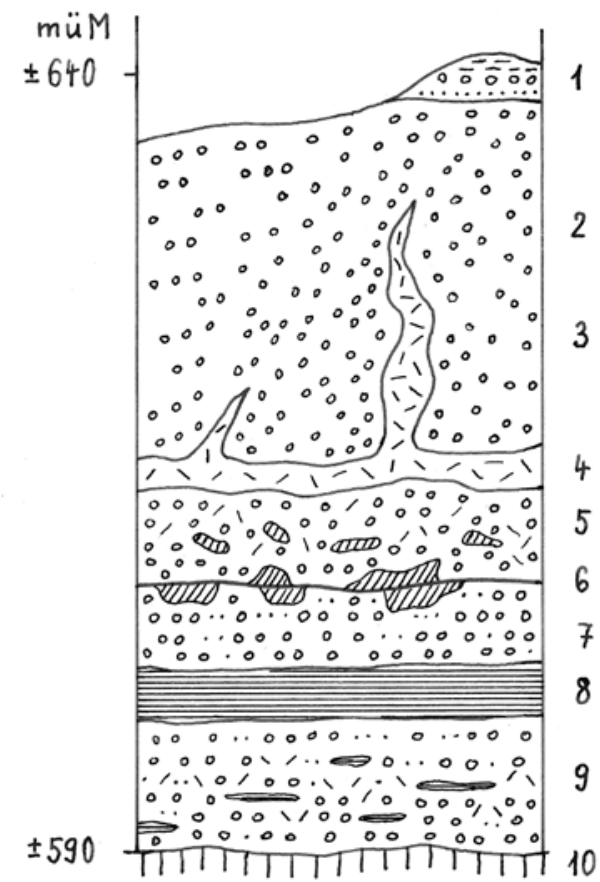

Abb. 12: Geologische Abfolge in der Kiesgrube Bittelschiess im Randbereich der Riss-Vergletscherung südöstlich Sigmaringen (umgezeichnet nach BIBUS \& KöSEL 1996). Auswertung siehe Tabelle.

Fig. 12: Geological record of the Bittelschiess gravel pit near the margin of the Riss galciation southeast of Sigmaringen (re-drawn after BIBUS \& KöSEL 1996). Analysis see table.
Eisrandlage des Doppelwall-Riss. Riss wird in dieser Arbeit generell als ein einziges Grossglazial aufgefasst, indem zwischen Zungenriss und Doppelwall-Riss sowie zwischen Doppelwall-Riss und Jungriss Interstadiale angenommen werden (SCHREINER 1992). Von Interglazialen, wozu keine Nachweise vorhanden sind, wird abgesehen.

Wie Schemmerhofen und Assmannshardt wird die Baltringer Terrasse (Abb. 11) von SchreINER (1996) morphostratigraphisch dem Doppelwall-Riss als Obere Hochterrasse zugeordnet. Da wie oben dargelegt die Äpfinger Terrasse (13 m-Terrasse) als Obere Hochterrasse aufgefasst werden kann, wird die Baltringer Terrasse um einen Glazialzyklus älter. Diese Auffassung wird durch die Untersuchungen von Bibus \& Kösel $(1996,2001)$ sowie von Miara et al. (1996) bestätigt, indem zwei fossile Böden, repektive ein fossiler Boden und eine Kiesverwitterung übereinander bestimmt werden konnten. Bei Baltringen kann unter Annahme von zwei Paläoböden der obere als Eem-zeitlich, der untere als um ein Interglazial älter angesehen werden. Der Schotterkörper müsste dementsprechend eine Eiszeit älter sein als Riss, wobei aber dazu keine Eisrandlage im Risstal bekannt ist. Das ältere Riss scheidet als stadialer Eisrand von Riss und nicht eigenständiges Glazial aus.

Auffallend ist, dass gemäss der geologischen Übersichtskarte des Iller-Riss-Gebiets (WEIDENBACH et al. 1988) nördlich von Baltringen keine oberen Hochterrassen vorkommen, hingegen die $13 \mathrm{~m}$-Terrasse des Jungriss bis Ulm deutlich zu verfolgen ist. Würde diese Terrasse dem Doppelwall-Riss zugeordnet, wie oben dargelegt, ergäbe sich eine der Mächtigkeit und Bedeutung des Doppelwall-Riss entsprechende Sander-Schüttung. Baltringen wäre dann ein Rest der nicht vollständig ausgeräumten oberen Hochterrasse eines um eine Eiszeit älteren Glazials.

Die zugehörige Vergletscherung hat offenbar die Über-

\section{Auswertung Profil KG Bittelschiess [Abb. 12]}

\section{Lithologie}

1 Rinnenkies, Feinsand, Silt

2 Schotter, z. T. gestaucht

3 in Kiese eingearbeitete Diamikte

4 Moräne, Diamikt

5 Schotter mit Bodenfetzen und Diamikten

6 Diskordanz mit Paläobodenresten

7 Schotter und Sande

8 Warvenartige Beckentone

9 Schotter mit eingearbeiteten Diamikten und Lehmen

10 Molasse, USM

\section{Genetische Interpretation}

Toteisloch-Füllung, Formumkehr

Eisrandnahe Schotter, glazialtektonisch gestört

durch Eisdruck hochgepresste Moräne

basale Moräne, Eisüberfahrung

eisrandnah, eingearbeitete Bodenteile und Diamikte

Bodenrelikt, diskordant abgeschert

Proglaziale, eisferne Schüttung

Beckensedimente, warmzeitl. Flora

Basale Ablagerungen bei Gletscherpräsenz

Glazial bearbeiteter Felsboden

\section{Glazialchronologie gemäß Bibus 8 Kösel 1996 \\ ElLWANger et al. 2011a}

Doppelwall-Riss [Innenwall]

Paulter Schwankung

Doppelwall-Riss [Außenwall]

Älteres Riss

IG Holstein

Hosskirch-Glazial

\section{Glazialchronologie} gemäß Autor

Riss-Spätglazial

Riss-Glazial, jüngerer Teil [Innenwall-Riss?]

Riss-Glazial, älterer Teil [Außenwall-Riss?] Vorstoß Riss-Gletscher

IG Meikirch

Schotter Habsburg-Glazial

IG Holstein

GRG Mindel

[Größtes Rheinisches Glazial]
Felsüberprägung im GRG Mindel 
laufschwelle aus dem Bodenseebecken zur Donau nicht überschritten, hingegen könnten Schmelzwässer nach Norden durch das Risstal abgeflossen sein (Kap. 5.1). Dabei wäre es zur Schüttung eines Hochterrassensystems gekommen, dessen von späterer Erosion verschonter Rest sich in der Hochterrasse von Baltringen erhalten hat (Abb. 11). Diese drittletzte Eiszeit hätte gemäß den Erkenntnissen im Raum Schaffhausen (GRAF 2009a, KELLER \& KRAYSS 2010) in etwa die Ausmaße von Würm erreicht und könnte als die diskutierte Habsburg-Vergletscherung angesehen werden. Da sie den Beckenrand nicht überschritt und ihre glazialen Bildungen von den nachfolgenden Riss-Gletschern weitflächig überfahren wurden, konnte sie im nördlichen und östlichen Rheingletschergebiet bisher nirgends direkt erkannt und nachgewiesen werden. In der Nordschweiz hingegen ist sie fassbar und in ihren Frontlagen rekonstruierbar (Abb. 10). Ihr nachgeschaltet ist das Interglazial von Meikirch anzunehmen (Preusser et al. 2005), dem der untere Boden von Baltringen zugewiesen werden könnte.

Im Biberach-Rissgebiet müsste gemäß diesen Erkenntnissen und Überlegungen folgende Glazial-Gliederung angenommen werden (Abb. 11):
Das in den Beckentonen identifizierte Interglazial ist mit Holstein gleichzusetzen, weshalb die liegenden Kiese und Diamikte älter sein müssen, das heißt sie sind nach den Erkenntnissen in der Nordschweiz dem GRG zuzuordnen. Auch Ellwanger et al. (2011a) vertreten die Zuordnung zum größten Glazial, das sie als Hosskirch bezeichnen (Kap. 4.1).

Davon ausgehend sind die über den Beckentonen liegenden Schotter als jünger zu betrachten, wobei auffällt, dass in diesem Paket keine Diamikte vorhanden sind, also wohl keine Eisüberfahrung erfolgt ist (Abb. 12). Die in der Nordschweiz erkannte Habsburg-Vergletscherung, die auf das Holstein-Interglazial folgte (KELLER \& KRAYss 2010), erreichte höchstens die räumlichen Ausmaße wie Würm. Daher kann auch für Bittelschiess damit gerechnet werden, dass in diesem Glazial höchstens Schmelzwässer aus dem Raum Pfullendorf zur Donau übergelaufen sind und den besagten Schotter zur Ablagerung gebracht haben (Abb. 10).

Entlang der darüber folgenden Diskordanz finden sich Reste eines Paläobodens, der ein nächstes Interglazial ausweist. Dieses dürfte das Meikirch-Interglazial repräsentieren, nicht aber das Eem, denn die hangenden, mächtigen Schotter, die zum Teil Moräne enthalten, können in dieser geographi-

\begin{tabular}{|c|c|c|c|}
\hline Bisher & $\underline{\mathrm{Neu}}$ & Terrassenstratigraphie & Interglaziale \\
\hline \multirow{2}{*}{ Würm } & Würm & Niederterrasse & \\
\hline & & & $\begin{array}{l}\text { Eem: Paläoböden } \\
\text { von Äpfingen und } \\
\text { Schemmerhofen, } \\
\text { oberer von Baltringen }\end{array}$ \\
\hline \multicolumn{4}{|l|}{ Riss: Jungriss } \\
\hline Doppelwall-Riss & Riss & Untere Hochterrasse: & \\
\hline Zungenriss & & $\begin{array}{l}13 \text { m-Terrasse Äpfingen } \\
\text { sowie Obere Hochterr., } \\
\text { z. B. Schemmerhofen }\end{array}$ & \\
\hline & & & $\begin{array}{l}\text { Meikirch: Unterer Paläo- } \\
\text { boden von Baltringen }\end{array}$ \\
\hline--- & Habsburg & $\begin{array}{l}\text { Obere Hochterrasse: } \\
\text { Terrasse von Baltringen }\end{array}$ & \\
\hline
\end{tabular}

\section{Krauchenwies/Bittelschiess}

Die große Kiesgrube Bittelschiess bietet seit Jahrzehnten Einblicke in eine sehr differenzierte Sedimentabfolge bei einer Abbautiefe von über $50 \mathrm{~m}$. Sie wurde insbesondere von Ellwanger (1990), Ellwanger et al. $(1995,1999)$ und Bibus ひ KöSEL $(1996,2001)$ eingehend untersucht. In ihren Publikationen kamen die Bearbeiter zum Schluss, dass sich in den Ablagerungen die Mehrphasigkeit von Riss, untergliedert durch Interglaziale oder Interstadiale manifestiere. Aus Untersuchungen von Bludau (schriftl. Mitt. in BiBus \& KöSEL 1996) geht hervor, dass das kräftige Band der Beckentone ein vollständiges Interglazial umfasst, gekennzeichnet durch Pterocarya und Buxus.

\section{Diskussion und Interpretation}

Das in Bibus \& Kösel (1996) in ihrer Abb. 10 dargestellte Gesamtprofil kann aufgrund der Einführung des bisher im nördlichen Bodenseeraum nicht festgestellten HabsburgGlazials sowie des Meikirch-Interglazials (KeLler \& KraYsS 2010) neu interpretiert werden (Abb. 12). schen und topographischen Lage nicht Würm sein. Die bis $40 \mathrm{~m}$ umfassenden oberen Schotter mit teils hochgepresster Moräne sind dem Riss-Glazial zuzuordnen, deren Gletscher bis an die Donau vorstiessen.

Differenziertere Erklärungen zu den Sedimentabfolgen und Bewertungen der komplexen Verhältnisse je nach Standort innerhalb des mächtigen Aufschlusses geben ELLWANGER et al. (2011a).

\subsection{Intraglazialbereich des nördlichen Bodenseebeckens}

\section{Hosskircher Becken}

Aus dem hauptsächlich nordgerichteten Schussenbecken zweigt das Nebenbecken von Hosskirch nach Nordwesten ab und zielt Richtung Ostrach, dem Übergang und Überlauf zum Donaugebiet. Etliche Tiefbohrungen wurden zur Erkundung der Beckenstruktur und der Sedimentfüllung niedergebracht. Anlass war die Suche nach geeigneten Zonen für Deponiestandorte. Die Auswertungen im Hinblick auf die 
Lithologie und Chronologie der Quartärsedimente sind publiziert in EllWANGer (1990, 1995), EllWANGER et al. (1995, 1999). Es ergab sich eine mehrphasige, teils diamiktische, teils kiesig-sandige Abfolge mit eingeschalteten warmzeitlichen Bildungen. Nachgewiesen wurden aufgrund der Pollenanalyse von Bludau (zitiert in EllwANGER et al. 1995) eine Buchen-Warmzeit, ein weiteres Interglazial, das jünger als Holstein, aber älter als Eem ist, sowie das Holstein-Interglazial. ELLWANGER konnte auch zeigen, dass das Hosskirch-Becken quer zu einem Strang der jüngeren, tieferen Deckenschotter angelegt ist und somit als solches jünger sein muss. In seiner jüngsten Publikation korrigiert Ellwanger (ELLwANGER et al. 2011a) die Pfefferbichl-Warmzeit in Eem und das ältere Riss in Hosskirch (Abb. 13, Auswertung).

\section{Diskussion und Interpretation}

Der Vergleich des Hosskirch-Beckens mit den Nordschweizer Becken (Keller \& Krayss 2010) ergibt einen gleichartigen lithostratigraphischen Aufbau, der eine Korrelation mit der dort erkannten Chronostratigraphie ermöglicht. Im Hosskirch-Becken, dessen Sedimente sehr genau untersucht worden sind (Ellwanger 1990, 1995, Ellwanger et al. 2011a), sind die Indizien für die postulierte Habsburg-Vergletscherung besonders überzeugend. Die Basis-Diamikte direkt über dem Beckenboden sind der Größten Vergletscherung zuzuordnen, die im Zuge der Beckenausschürfung zum Absatz kamen, was gemäss EllwANGER et al. (2011b) „Hosskirch" entspricht. Die darüber anschließenden Feinsedimente enthalten nach Bludau (zitiert in ELLWANGER et al. 2011a) das Holstein-Interglazial. Im Hangenden folgt ein Diamikt, der das Habsburg-Glazial widerspiegeln dürfte, dessen Gletscher das Hosskirch-Becken zwar noch überfahren, jedoch das Donau-Hochgebiet nicht mehr erreicht haben (Abb. 10). In den überlagernden Feinsedimenten findet sich gemäss Bludau ein nicht klar definierbares Interglazial, das das Meikirch-Interglazial repräsentieren dürfte. Im Hangenden folgt Moräne, die das gesamte Riss-Glazial widerspiegelt, indem Riss im Gegensatz zu EllwANGer et. al. (1999) als eine einzige Großvergletscherung aufgefasst wird (siehe Abschnitt Risstal-Biberach). Zwischen die liegende und die hangende, oberste Moräne greifen Feinsedimente ein, in denen durch Bludau die Buchen-Warmzeit festgestellt wurde. Sie kann als eine post-Eem-Warmzeit stellvertretend für das Eem angesehen werden, das hier in der typischen Ausprägung offenbar fehlt. Die abschließenden, die Oberfläche bildenden Moränen sind Teil der würmzeitlichen Gletscherfront.

\section{Taubenried bei Pfullendorf}

Ausstrahlend vom Pfrunger Ried erstreckt sich östlich Pfullendorf ein kleines Zweigbecken nach Nordwesten, das Taubenried. Es unterschneidet den Außenmoränenkranz der Würm-Maximalvergletscherung. Dieses Becken ist in seiner Tiefe und in seiner Sedimentfüllung anhand von Bohrungen, die von EllwANGer (1990) ausgewertet worden sind, bekannt geworden. ELLWANGER erkennt darin drei glaziale Sequenzen, die er dem Doppelwall-Riss, dem Jungriss und dem Würm zuweist, wobei er die Beckenausräumung im Unteren Riss sieht (Abb. 14, Auswertung).

\section{Diskussion und Interpretation}

Das wenig westlich von Hosskirch gelegene Taubenried-Be-

\section{Quartärgeologisches Profil durch das Hosskirch-Becken südöstlich Saulgau \\ aufgezeichnet nach Ellwanger 1995, 2011 a \\ Pollenanalyse Bludau}

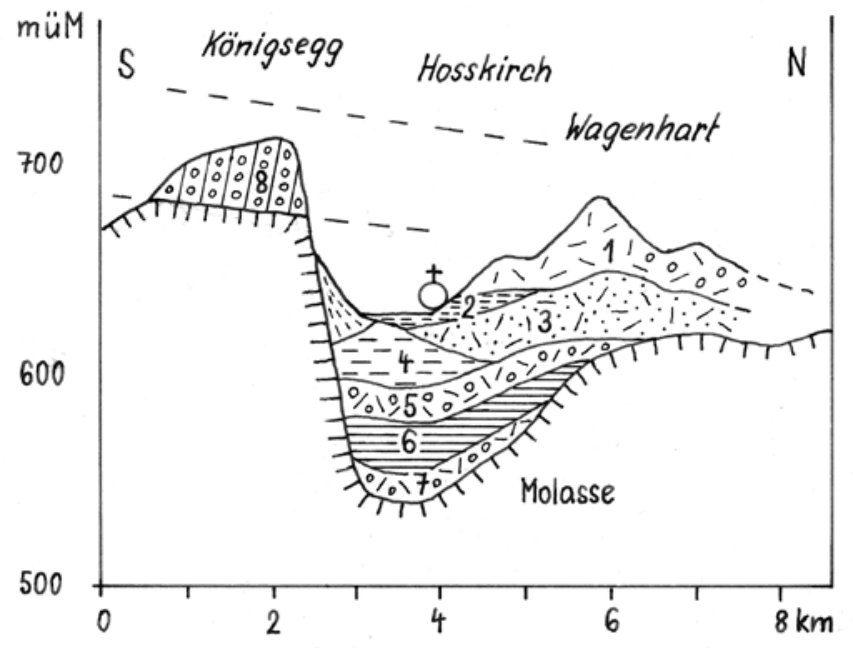

Abb. 13: Geologischer Querschnitt durch das Becken von Hosskirch bei Saulgau (nach ELLWANGER 2011a). Auswertung siehe Tabelle.

Fig. 13: Geological cross section through the Hosskirch basin near Saulgau (based on ELLWANGER 2011a). Analysis see table.

cken kann entsprechend zu dort interpretiert werden, wobei allerdings infolge Mangels an Zeitmarken (Bodenbildungen, Pollenanalyse) Spielraum für Zuweisungen offenbleibt. Die Beckenausräumung ist wie vielenorts im Zusammenhang mit der Größten Vergletscherung GRG zu sehen. Die basalen Sande können als vermutlich eisfreie Periode dem HolsteinInterglazial entsprechen. Darüber anschließende Schotter (Vorstoßschotter) werden von Moräne überlagert. Diese Sequenz könnte im Habsburg-Glazial eingestuft werden, da in dieser mit Hosskirch vergleichbaren geographischen Lage diese Vergletscherung das Becken noch überfahren haben müsste (Abb. 10).

Die über 20 m mächtigen, hangenden OSM-Sande scheinen, wie es von Ellwanger (1990) angenommen wird, eine bedeutende Zeitspanne mit Eisfreiheit auszuweisen, was dem Meikirch-Interglazial entsprechen würde. Darüber abgelagerte Diamikte und Schotter enthalten wahrscheinlich die gesamte Riss-Eiszeit, deren Eisrandlagen (DoppelwallRiss, aber auch Jungriss) weiter nördlich zu finden sind. In der östlicheren Bohrung angetroffene Verwitterungslehme sind entsprechend Ellwanger Indizien für das nächst jüngere Interglazial Eem. Sie werden überdeckt von Seesedimenten als Übergang zum folgenden Glazial, das durch Moräne belegt ist, die ihrerseits als Würm-Ablagerungen anzusprechen sind. Die westliche Bohrung liegt bereits ausserhalb der würmmaximalen Frontwälle und durchstösst die Sanderkiese der Niederterrasse.

\section{Wattenweiler östlich Schussenried}

Unterstützt von einer Profildarstellung beschreibt ElLwANGER (1995) eine Bohrung bei Wattenweiler, die knapp innerhalb der Wälle des Würm-Maximums abgeteuft wurde. Er stellt über einem markanten Hiatus zuerst Schotter und da- 
1 Moräne und Kiese

2 Feinsedimente mit warmzeitlicher Flora

3 Diamikte, Grundmoräne

4 Feinsande und Silte, warmzeitliche Flora

$5 \quad$ Konsolidierte Diamikte

$6 \quad$ Feinsedimente mit warmzeitlicher Flora

7 stark konsolidierte Diamikte
Frontaler Moränenwall

Interglazial; gemäß Bludau

„Buchen-Warmzeit"

Moränendecke, Eisüberfahrung

Älteres Interglazial, jünger als Holstein gemäß Bludau

Moräne eines Gletschervorstoßes

Älteres Interglazial vom Typ Holstein

Vergletscherung mit Beckenbildung und basaler Moräne

Tieferer Deckenschotter
Glazialchronologie gemäß ELLWANGer 1990 [2011a]

Würm-Eiszeit, LGM

IG „Buchen-Warmzeit“

Jungriss-Vergletscherung

Warmzeit Typ „Pfefferbichl“ [oder Eem-Interglazial?]

Doppelwall-Riss

Samerberg-HolsteinWarmzeit

Älteres Riss

[Hosskirch]

Glazialchronologie gemäß Autor

Würm-Glazial

IG [Eem fehlt] gesamtes Riss-Glazial

IG Meikirch

Habsburg-Glazial

IG Holstein

GRG [Größtes

Rheinisches Glazial]

Mindel-Deckenschotter rüber mehrere Diamiktserien fest, die er gesamthaft einem Eisvorstoß der frühen Würm-Eiszeit zuordnet. Darüber lagern Feinsedimente mit einer warmzeitlichen Flora (Buchenwaldzeit gemäß Bludau zitiert in ElLwANGER 1995). Erst im Hangenden nimmt Ellwanger das Hochwürm an, repräsentiert durch Diamikte, Kiese und Sande (Abb. 15).

Unter dem Hiatus finden sich Diamikte unterlagert von Feinsedimenten, in denen Bludau eine Warmzeit vom Typ Samerberg-Holstein nachweisen konnte. Schliesslich folgen im Liegenden um die $30 \mathrm{~m}$ Diamikte bis zur anstehenden Molasse. Diese gesamte Sequenz positioniert Ellwanger im älteren und im Doppelwall-Riss, wobei er Riss in zwei eigenständige Eiszeiten, getrennt durch ein Interglazial, unterteilt.

\section{Diskussion und Interpretation}

Für die Beckenbildung und die basalen Diamikte ist die Vergletscherung des GRG = Hosskirch anzunehmen, folgt doch darüber das Holstein-Interglazial (Abb. 15). Die hangenden Diamikte sind dann Zeugen eines nächst jüngeren Glazials, das als Habsburg anzusprechen wäre, ausgehend von der Erkenntnis, dass diese Vergletscherung ausdehnungsmässig in etwa dem Würm entspricht und damit Wattenweiler noch erreicht haben müsste (Abb. 10). Der Hiatus dürfte dem vor dem nächsten glazialen Zyklus fehlenden Interglazial Meikirch entsprechen. Die Schotter und Diamikte über dem Hiatus sind somit ins Riss zu stellen, das mehrere Eisrandlagen mit wohl größeren Oszillationen aufweist, die sich in den verschiedenen Diamikten äußern.

Es sind zwar ein, eventuell zwei Frühwürm-Gletschervorstöße bekannt (SCHLÜCHTER et al. 1987, WINISTORF 1987, Keller \& Krayss 1998, Preusser 1999), die aber bedeutend geringere Ausmasse hatten als die Hochwürm-Vergletscherung. Wattenweiler in Frontnähe des Würm-Maximums wurde jedenfalls nicht erreicht. Die von ElLwANGER (1995) dem älteren Würm zugeschriebenen Moränenablagerungen über dem Hiatus sind demzufolge als risszeitlich anzusehen. Die in den darüber folgenden Feinsedimenten festgestellte Buchenwarmzeit ersetzt hier das fehlende typische Eem.
In den hangenden Sedimenten inklusive Diamikte ist die Würm-Vergletscherung dokumentiert.

\section{Singener Becken}

Das Singener Becken, die Tiefzone des Hegaus, ist von mittel- und spätpleistozänen Sedimenten erfüllt und umgeben von eisrandlichen Ablagerungen und Wallformen, die überwiegend der Würm-Eiszeit angehören (ERB 1934, SchrEINER 1974). Unter Einbezug von Bohrungen gibt SCHREINER (1992, Abb. 93) eine Übersicht zu den spätpleistozänen, würmzeitlichen Ablagerungen am und im Singener Becken.

Mit einer Serie von Bohrungen wurden in den 1990er Jahren die Teilbecken und deren Füllungen des gesamten Singener Beckens erforscht. SzENKLER \& Bock (1999) untersuchten die Bohrprofile und zeigten auf, dass das Großbecken sich in zahlreiche Teilbecken aufgliedert. Als typisches Beispiel wurde die Kernbohrung 1/1997 Rielasingen-Worblingen lithound chronostratigraphisch interpretiert (Abb. 16). Es wurden dabei vier Glaziale aufgrund der Diamiktlagen ausgeschieden und vier Eiszeiten zugeordnet, wobei Doppelwall-Riss und Jungriss als eigenständige Glaziale aufgefasst werden. In einer anderen Bohrung wurden basal umgelagerte Pollen eines älteren Interglazials (süddeutsches Cromer) gefunden. In den Basissedimenten einer weiteren Bohrung konnten für die Warmzeit vom Typ Samerberg-Holstein charakteristische Pollen identifiziert werden (SzENKLER \& Bock 1999, mündl. Mitt. Bludau).

\section{Diskussion und Interpretation}

In Übereinstimmung mit SzenkLer \& Bock (1999) wird die Beckenbildung zusammen mit dem basalen Till in die Größte Vergletscherung = Hosskirch gestellt, gestützt auf die Pollenfunde (mündl. Mitt. Bludau). Hingegen können die zwei nahe beieinander liegenden, über einem Sand-Kies-Horizont folgenden Moränenhorizonte (Till) zwanglos in die Habsburg-Eiszeit eingestuft werden, umso mehr als darüber eine durch Sande und Silte ausgewiesene Seenphase anschließt, die für das Spät- und Post-Habsburg charakteristisch ist 


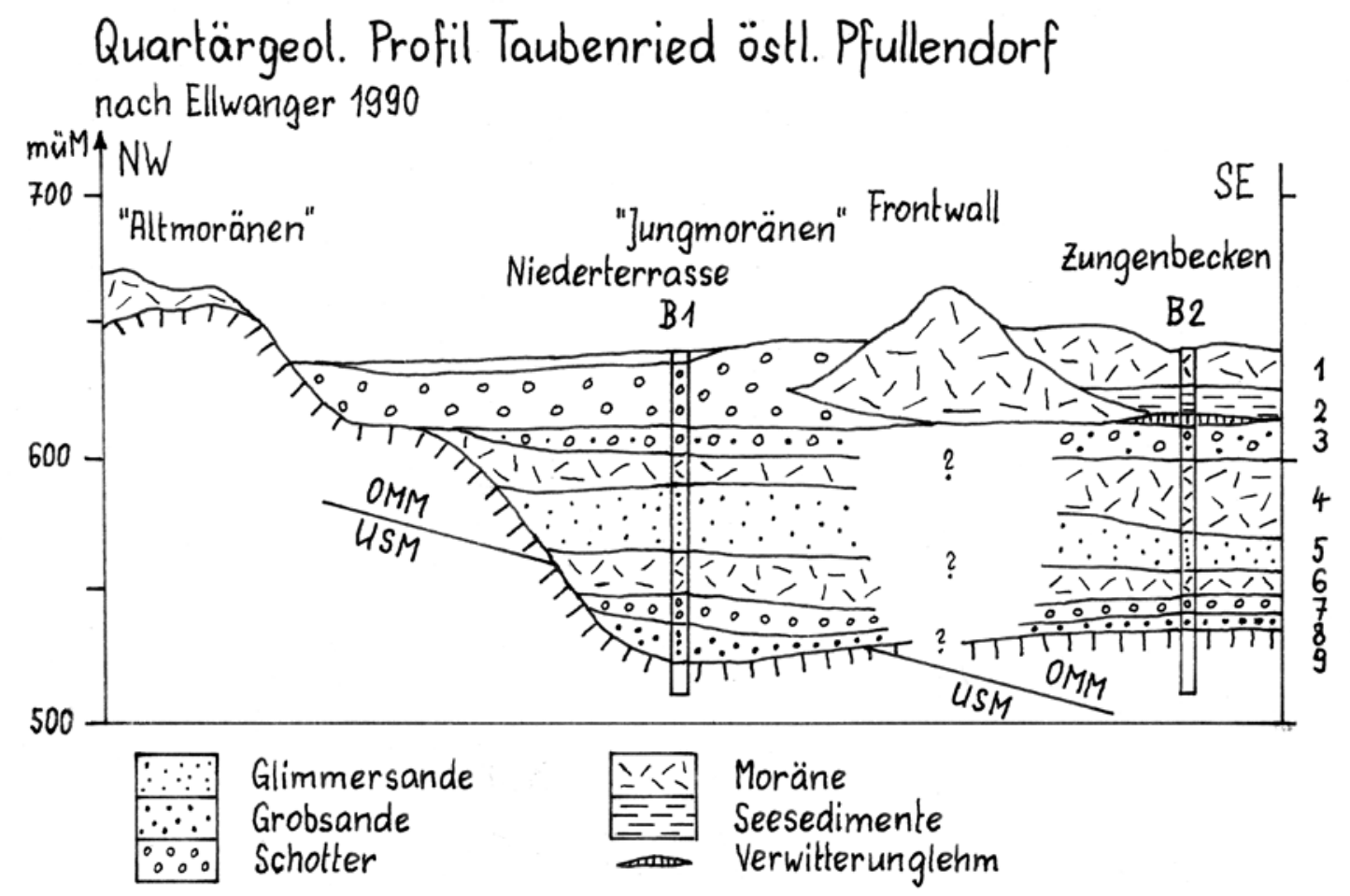

Abb. 14: Geologischer Querschnitt durch das Taubenried-Becken östlich Pfullendorf (nach ELLWANGER 1990). Auswertung siehe Tabelle. Fig. 14: Geological cross section through the Taubenried basin in the east of Pfullendorf (based on ELLWANGER 1990). Analysis see table.

\begin{tabular}{|c|c|c|c|c|}
\hline & \multicolumn{4}{|c|}{ Auswertung Profil Taubenried [Abb. 14] } \\
\hline & Lithologie & Genetische Interpretation & $\begin{array}{l}\text { Glazialchronologie } \\
\text { gemäss ELLWANGER } 1990\end{array}$ & $\begin{array}{l}\text { Glazialchronologie } \\
\text { gemäss Autor }\end{array}$ \\
\hline 1 & $\begin{array}{l}\text { Diamikt, Moräne, } \\
\text { im W Kiese }\end{array}$ & $\begin{array}{l}\text { Grund- und Obermoräne, } \\
\text { Gletscherfront, im W Sander }\end{array}$ & $\begin{array}{l}\text { Würm-Eiszeit, } \\
\text { Maximalstand }\end{array}$ & $\begin{array}{l}\text { Würm-Glazial, } \\
\text { Würm-Maximum }\end{array}$ \\
\hline 2 & $\begin{array}{l}\text { Feinsedimente, } \\
\text { Verwitterungslehm }\end{array}$ & $\begin{array}{l}\text { Stillwasser-Sedimente, basal } \\
\text { Verwitterung warmzeitlich }\end{array}$ & Warmzeit, Eem & IG Eem \\
\hline 3 & Grobsande, Kiese & Aufschüttung nach Eisfreigabe & Rückschmelz-Sequenz & Spätriss \\
\hline 4 & Diamikt & Grundmoräne einer Eisüberfahrung & Jungriss-Vergletscherung & Riss-Glazial \\
\hline 5 & Glimmersande & umgelagerte Sande, eisfreie Periode & eisfrei, Warmzeit & IG Meikirch \\
\hline 6 & Diamikt & Grundmoräne, Eisüberfahrung & Mittelriss-Vergletscherung & Habsburg-Glazial \\
\hline 7 & Kiese & Vorstossschotter & Vorstoss Riss-Gletscher & Vorstoss Habsburg-Gletscher \\
\hline 8 & Sande und Grobsande & Stillwasser-Sedimente & eisfreie Periode & Warmzeit, IG Holstein \\
\hline 9 & Molasse-Felsbett & Exariertes Glazialbecken & $\begin{array}{l}\text { Beckenbildung im } \\
\text { Älteren Riss }\end{array}$ & $\begin{array}{l}\text { Beckenausschürfung im } \\
\text { GRG }\end{array}$ \\
\hline
\end{tabular}

(Keller \& KraYss 2010). Damit sind die mehrfachen Diamikte des mittleren Profilabschnittes nicht nur Jungriss, sondern dürften das gesamte Riss umfassen. Dabei wird davon ausgegangen, dass, wie oben gezeigt, der gesamte Riss-Komplex ein einziges Glazial darstellt. Abschließend folgen noch unzweifelhafte Würm-Moränen.

\subsection{Ausblick zum Illergletscher}

Wenn das Habsburg-Glazial in der Nordschweiz als gesichert gelten kann (Graf 2009a, Keller \& Krayss 2010) und nun auch im nördlichen Rheingletschergebiet eine Reihe Indizien dafür spricht, so müssen auch beim östlichen Nachbarn des Rheingletschers, beim Illergletscher, Hinweise für ein Glazial, das sich zwischen das größte Glazial, hier Mindel, und die Riss-Eiszeit einschiebt, zu finden sein.

Penck (Penck \& BRÜCKner 1909) hat im IllergletscherVorland aufgrund der Höhenlagen der Schotterfelder Riss und Würm morphostratigraphisch erfasst und definiert. Dabei erkannte er zwar die ungleichen Niveaus des Hitzenho- 


\section{Bohrprofil Wattenweiler östl. Schussenried umgezeichneter Auszug aus Ellwanger 1995}

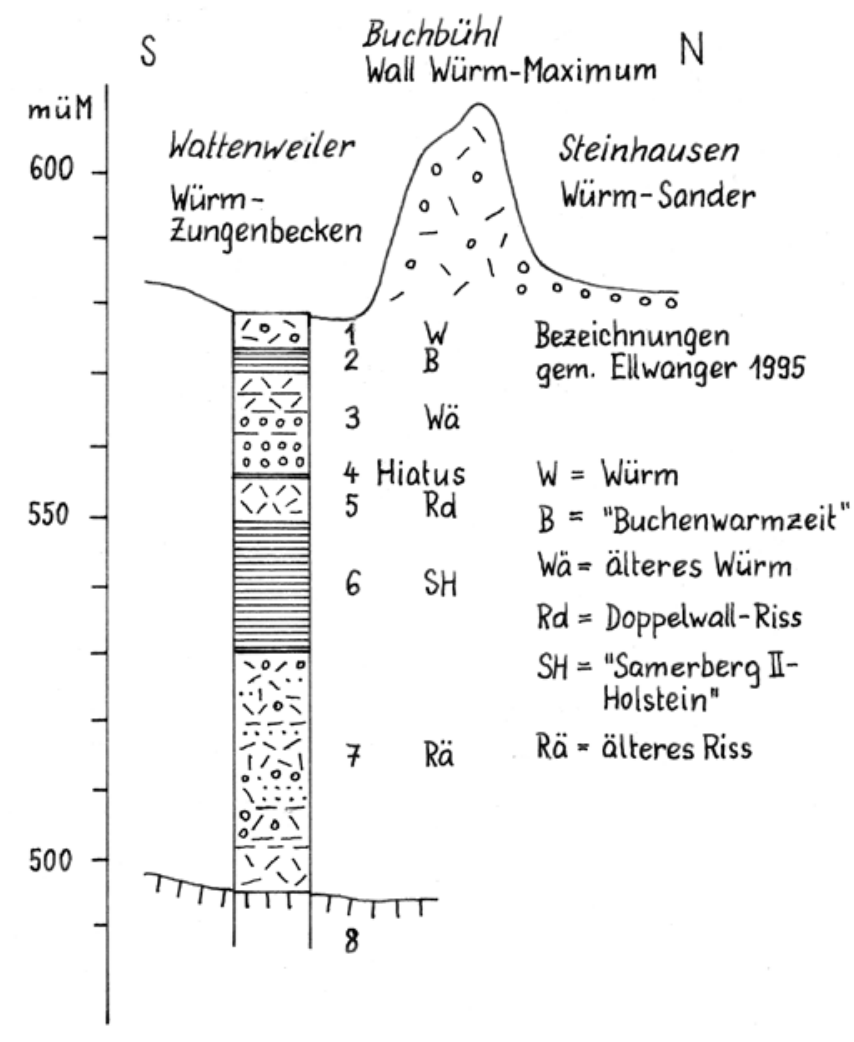

Abb. 15: Geologisches Profil der Bohrung Wattenweiler östlich Schussenried (umgezeichnet nach ELLWANGER et al. 1995). Auswertung siehe Tabelle.

Fig. 15: Geological profile of the Wattenweiler drilling in the east of Schussenried (re-drawn after ELLWANGER et al. 1995). Analysis see table. fer Feldes und des Zeller-Hawanger Feldes (Abb. 17) sowie die verschiedenen Abflussbahnen aus dem Vergletscherungsraum über diese Schotterfelder. Er wies aber beide Systeme derselben Eiszeit, der Riss-Eiszeit zu. RöGNER (1998) unterschied im Raum Memmingen vier Felder, die er entsprechend auch vier Eiszeiten zuordnete.

Auf dem Hitzenhofer Feld (Abb. 17) wurde von BiBus (1995) bei drei Höfen je ein fossiler Boden erkannt, wobei beim Hof Baltes unter dem ersten fossilen Boden eine direkt folgende Kiesverwitterung als unsicherer zweiter fossiler Boden beschrieben wird. Hingegen weist das Hawanger Feld nach Bibus an zwei Stellen je zwei fossile Böden übereinander auf.

\section{Diskussion und Interpretation}

Aufgrund von Penck's Konzept der treppenweisen Eintiefung und Einschachtelung der jüngeren Schotterfelder jeder Eiszeit in die älteren müsste dem Zeller-Hawanger Feld eine eigene Eiszeit zugewiesen werden (Vergleiche auch ELLwANGER 1988).

Aufgrund der Befunde bei den Nordschweizer Gletschern sowie beim Rheingletscher kann die Aussengrenze einer Habsburg-Vergletscherung auch beim Illergletscher maximal die Ausdehnung von Würm erreicht haben. Darauf basierend erklärt sich das Fehlen eines Endmoränensystems, an dem das Zeller-Hawanger Feld wurzelt, zwanglos, wenn von einer Vergletscherung ausgegangen wird, die intern im Illerbecken endete und deren Zeugen von den nachfolgenden Riss- und Würmgletschern ausgemerzt oder eingedeckt worden sind (Abb. 9).

Für das Hitzenhofer Feld ergibt sich gemäß BiBus (1995) an drei Lokalitäten je ein sicherer fossiler Boden, was für die Bildung der Terrassenkiese in der zweitletzten Eiszeit Riss

Auswertung Bohrung Wattenweiler [Abb. 15]

Lithologie

1 Diamikte, darin eingebettet Kiese und Sande

2 Feinsedimente mit Warmzeitlicher Flora

3 Schotter, darüber mehrere Diamikt-Horizonte

$4 \quad$ Hiatus, Diskordanz

5 Diamikte, stark konsolidiert

6 Feinsedimente, Silte, Ton

7 Diamikte, stark konsolidiert, mit Einbettung von Sanden, Silten, Kieslagen

8 Molassefels der USM

\section{Genetische Interpretation}

Eisrandnahe Grund- und OberMoräne mit Schottern und Sanden

Interglaziale Seesedimente mit „Buchenwarmzeit”

Vorstoßschotter, überlagert mit Moränen und Schotterlagen; Eisüberfahrung

durch Eisvorstoß abgescherte Sedimente? Vermutlich Warmzeit

Grundmoräne einer GletscherÜberfahrung; konsolidiert infolge Überlagerung und Eisdruck

Mächtige Seesedimente, Beckenfüllung; Interglaziale Flora vom Typ Holstein mit Pterocarya

Wechsellagerung von Grundmoräne und kiesigen Horizonten; durch Überlagerung konsolidiert

Exariertes glaziales Becken

\section{Glazialchronologie} gemäß ELLWANGER 1995

Würm-Eiszeit

nahe Würm-Maximum

Buchenwarmzeit als Frühwürm-Interstadial

Eisvorstoß im frühen Würm: „Älteres Würm“

Hiatus

Gletscher-Vorstoß von

Doppelwall-Riss als

eigenständiges Glazial

Holstein- Interglazial, trennt Älteres Riss vom

Doppelwall-Riss

Gletscher-Vorstoß des Älteren Riss als eigenständiges Glazial

Becken-Ausschürfung im Älteren Riss
Glazialchronologie gemäß Autor

Würm-Glazial: Würm-Maximum

Warmzeit; Eem fehlt

Riss-Glazial: gesamtes Riss mit Interstadialen

Diskordanz. Vermutlich IG Meikirch erodiert

Habsburg-Glazial

IG Holstein

Basale Glazialsedimente des GRG

Beckenausschürfung durch GRG-Gletscher 
spricht. Die Schüttung des Hawanger Feldes mit zwei fossilen Böden übereinander ist in die drittletzte Eiszeit zu legen, nach bisheriger Meinung die Riss 1-Vergletscherung. Nach der hier vertretenen Ansicht, die nur von einer einzigen RissEiszeit ausgeht (siehe Risstal-Biberach, Kap. 5.2), kann dieses drittletzte Glazial der postulierten Habsburg-Vergletscherung entsprechen, die sich mit dem unteren fossilen Boden als Interglazial-Zeuge klar von Riss absetzt. Damit ist das ZellerHawanger Feld nicht in das gleiche Glazial einzustufen wie das Riss-zeitliche Hitzenhofer Feld, vielmehr ist anzunehmen, dass es der nächst älteren Eiszeit, dem Habsburg-Glazial mit dem Status eines eigenständigen Glazials, angehört.

\section{Charakteristik der Glaziale im nördlichen Rheingletschergebiet}

Die folgende Kurzbeschreibung geht von den vorstehend dargelegten Befunden und Indizien für vier mittel- und spätpleistozäne Glaziale aus. Einerseits wird ein Größtes Rheinisches Glazial GRG, nach ELLwANGER (2003) MEG, nach VILlinger (2011) Hosskirch, das älter als Riss, aber jünger als die jüngeren Deckenschotter einzustufen ist, angenommen (Kap. 4). Anderseits wird bei Akzeptanz der Indizien ein selbständiges Habsburg-Glazial eingeführt, das sich zwischen GRG = Hosskirch und Riss einschiebt (Kap. 5).

\section{Größtes Rheinisches Glazial GRG = Hosskirch}

Eiszeit,

- deren Gletscher in einer „Eisüberflutung“ die größte Ausdehnung aller Vergletscherungen erreichten;

- die für die Ausschürfung des Bodensee-Hauptbeckens und der meisten Nebenbecken verantwortlich ist;

- die auf breiter Front die Donau zwischen Sigmaringen und Riedlingen noch überschritt und zwischen Bussen, Biberach und Aitrach die äußersten Wallmoränen schuf; - die die einstigen Donauläufe von Sigmaringen bis Riedlingen verschüttete und den heutigen südlicheren Lauf induzierte.

\section{Habsburg-Glazial}

Eiszeit,

- deren Gletscherfront die Wasserscheide Rhein-Donau

knapp erreichte, aber nicht mehr überfuhr;

- deren frontale Eisrandbildungen durch die nachfolgenden Eiszeiten überfahren und/oder zerstört wurden;

- deren glaziale Sedimente in den Bodensee-nahen Becken teilweise erhalten blieben oder später ausgeräumt wurden; - deren Schmelzwässer nebst der Rheinachse nach Westen höchstens während der Maximalvereisung wenige Abflussbahnen zur Donau fanden.

\section{Riss-Glazial}

Eiszeit,

- deren Eisströme über die Rhein-Donau-Wasserscheide hinweg sich ausbreiteten, zwischen Mengen und Riedlingen bis an die Donau reichten und im Raum Riss-Aitrach markante parallele Wälle (Doppelwall-Riss) hinterliessen; - die innerhalb ihrer Außengrenze umfangreiche glaziale Sedimente zur Ablagerung brachte;

- die verantwortlich ist für den Durchbruch der Aitrach aus dem Leutkircher Becken zur Iller.

\section{Bohrprofil Rielasingen-Worblingen umgezeichnet nach Szenkler \& Bock 1999}

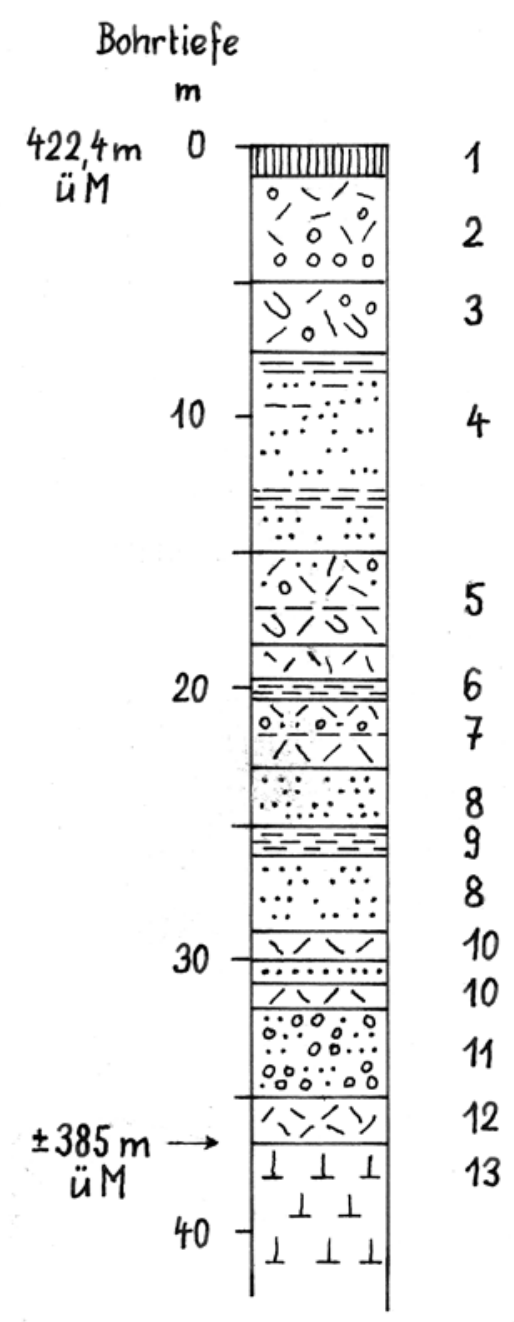

Abb. 16: Geologische Abfolge in der Bohrung Rielasingen-Worblingen, westliches Bodenseebecken (umgezeichnet nach SZENKLER \& BOCK 1999). Auswertung siehe Tabelle.

Fig. 16: Geological record of the Rielasingen-Worblingen drilling, western part of the Lake Constance basin (re-drawn after SZENKLER \& BOCK 1999). Analysis see table.

- deren Sander im Norden (Donau) und im Nordosten (RissIller) als Hochterrasse in zahlreichen Relikten erhalten sind.

\section{Würm-Glazial}

Eiszeit,

- deren äußerste Zungen bis auf die Wasserscheide RheinDonau vorrückten und dort teils mächtige Frontmoränenwälle anhäuften;

- die sich in den Becken in gut erhaltenen Diamikten manifestiert;

- deren Schmelzwässer über zahlreiche Schwellen zwischen Homburg (westlich Messkirch) und Adelegg nordwärts zur Donau und ostwärts zur Iller abflossen;

- in deren Entwässerungsbahnen die Niederterrassen eingeschüttet wurden;

- deren zentraler Eisstrom das Bodenseebecken großenteils ausräumte und beim Abschmelzen den Bodensee entstehen liess. 


\section{Lithologie}

Genetische Interpretation

1

2

Diamikt und

Schotter

$3 \quad$ Diamikt mit Umlagerung

$4 \quad$ Feinsedimente, Sande

$5 \quad$ Diamikt

Diamikt-Umlagerung

6 Ton, Silt

7 Diamikte

8 Sande

9 tonige Feinsedimente

8 Sande

10 Till

11

12

13
Till

Sande und Kiese

OSM
Gletscher-Überfahrung

begrenztes Rückschmelzen

Gletscher-Vorstoß und

Überfahrung

See-Sedimente

Gletscher-Vorstoß

mit Oszillationen

Stillwassersedimente

Seesedimente

Gletscher-Vorstoß

mit Oszillation

Rückschmelz-Sedimente

Moräne, Eisüberfahrung
Glazialchronologie gemäß

SZenkLer \& Bock 1999

Glazialchronologie

gemäß Autor
Würm-Glazial

[Stein a/Rh-Stadial?]

Last Glacial Maximum

eisfreie Periode

Jungriss

eisfreie Periode

Doppelwall-Riss

eisfrei

Most Extensive Glaciation
Würm-Glazial

[Maximum]

IG Eem, Seenphase

gesamtes Riss-Glazial

IG Meikirch?

[ausgeprägte

Seenphase]

Habsburg-Glazial

IG Holstein? [Hinweise aus anderer Bohrung]

GRG [Größtes

Rheinisches Glazial]

Beckenbildung im GRG

\section{Schlussfolgerungen und Chronostratigraphie}

Aus den in den vorstehenden Kapiteln dargelegten Befunden ergeben sich gute Hinweise darauf, dass im nördlichen Bodenseegebiet für das Mittel- und Spätpleistozän nebst den bekannten Eiszeiten Riss und Würm höchst wahrscheinlich zwei weitere Glaziale anzunehmen sind. Der Zeitraum dieser vier Glaziale beginnt nach der Ablagerung der Tieferen Deckenschotter mit der Umlenkung des Alpenrheins von der Donau zum Oberrhein und der damit verbundenen starken und tiefen Durchtalung im Bodenseeraum und in der Nordschweiz. Die daran anschließenden Eiszeiten führten zur charakteristischen Beckenbildung und zu übertieften Trögen im Randalpengebiet und im Vorland. Sie können deshalb im Gegensatz zu den Deckenschotter-Eiszeiten als Becken-Eiszeiten bezeichnet werden. Die erste und älteste dieser Eiszeiten und gleichzeitig diejenige mit der größten Ausdehnung ist das Größte Rheinische Glazial GRG, für das in LGRB (2003) die Bezeichnung Hosskirch eingeführt wurde. Für das nächstfolgende Glazial, das im nördlichen Bodenseeraum bis jetzt unbekannt war, in der Nordschweiz aber nachgewiesen ist, das Habsburg-Glazial (GRAF 2009a; KeLler \& KRAYss 2010), konnte eine Reihe von Indizien gefunden werden. Erst daran anschliessend folgen die Rissund die Würm-Eiszeit.

Die Untersuchungen und Nachforschungen führten zur Erkenntnis, dass im gesamten nördlichen Bodenseeraum eine und dieselbe Vergletscherung die äußerste Grenze der Glazialrelikte hinterlassen hat, die postulierte Vergletscherung des Größten Rheinischen Glazials GRG (Kapitel 4).
Sie muss älter sein als Riss, denn es finden sich an einigen Stellen Schotter und glaziale Diamikte liegend unter Ablagerungen der Riss-Eiszeit. Im Nordwesten des Bodenseebeckens wurde bis vor kurzem Riss (Riss nach traditioneller Auffassung) als größte Vergletscherung betrachtet. In Übereinstimmung mit ElLwANGER (2003) und EllwaNGER et al. (2011a) kann gezeigt werden, dass die Riss-Vergletscherungsgrenze, morphologisch und sedimentär begründet, zwischen Homburg (NW Stockach)-Messkirch-Riedlingen deutlich intern der über die Donau hinausreichenden, äußersten Vergletscherungszeugen des GRG liegt.

Der mehrfache Nachweis des Holstein-Interglazials in Sedimenten im Hangenden derjenigen des GRG = Hosskirch, aber im Liegenden der Riss-Ablagerungen, respektive der als Habsburg angesprochenen Sedimente, ermöglicht die Trennung der Glaziale.

Im Nordosten und Osten des Bodenseebeckens sind die externsten Moränendecken und niedrigen Moränenwälle sowie die dazugehörigen Entwässerungsbahnen bisher in die Mindel-Eiszeit gestellt worden. Da diese Vergletscherungszeugen wie im Nordwesten eine ausgedehntere und ältere Eiszeit als Riss belegen, ist auch hier von der Zugehörigkeit zum Größten Rheinischen Glazial GRG auszugehen. Sie weisen zudem dieselben morphologischen Charakteristika auf wie jene. Im Weiteren ergibt die Eiskörper-Rekonstruktion des GRG (Abb. 4) ein plausibles dreidimensionales Bild.

Das Postulat von GRG $=$ Hosskirch im östlichen Rheingletschergebiet als ausgedehnteste Vergletscherung dürfte hier „Mindel“ ablösen mit gravierenden Konsequenzen: 


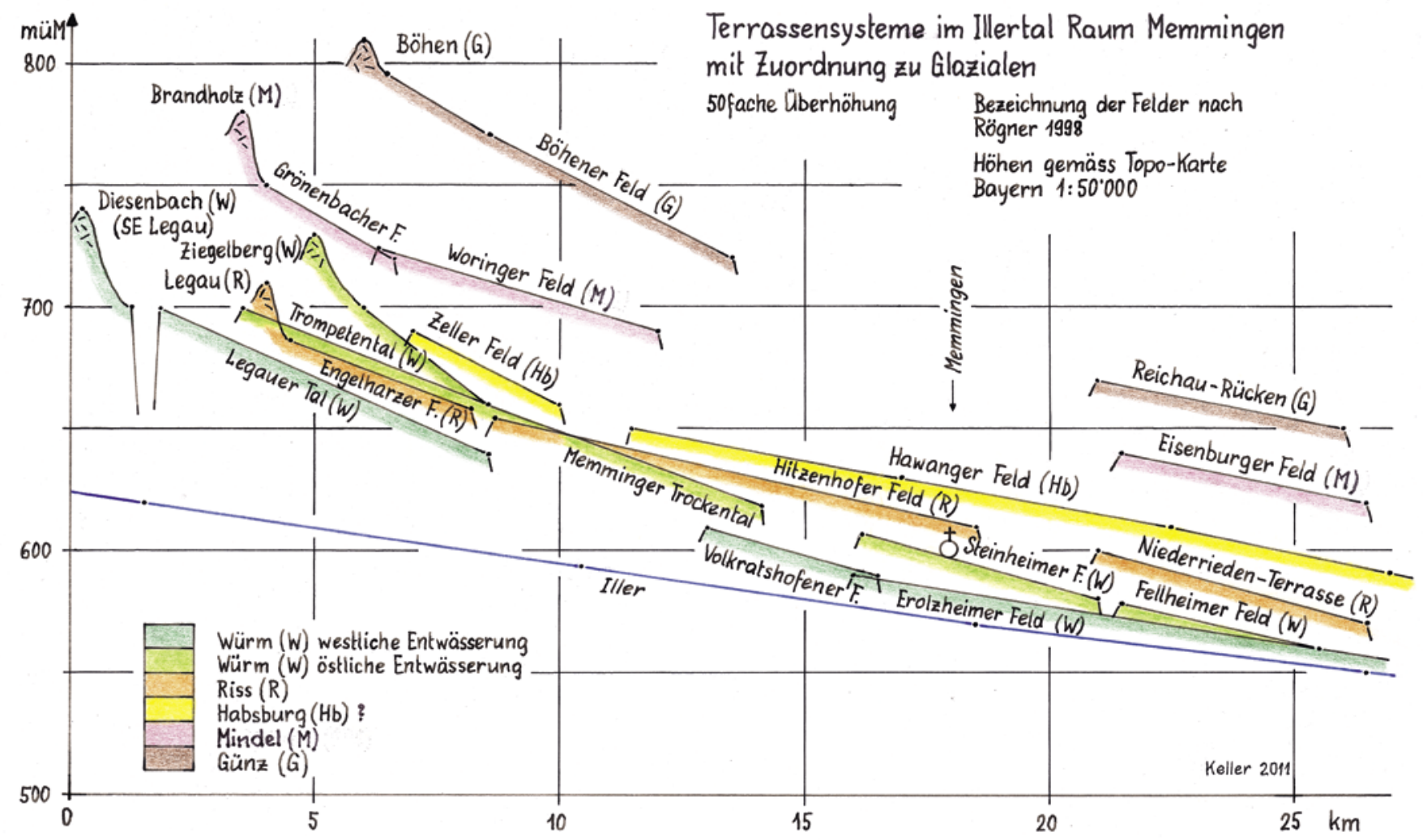

Abb. 17: Abfolge der Sander-Terrassen des Illergletschers im Raum Memmingen; S-N-Projektion.

Fig. 17: Succession of the outwash terraces of the Iller Glacier in the region of Memmingen; S-N-projection.

1. Im Nordosten und Osten des Rheingletscher-Ausbreitungsbereichs würden die als Mindel bekannten Moränen nicht mehr in die Zeit der Deckenschotter fallen, sondern sie wären dem Größten Rheinischen Glazial GRG $=$ Hosskirch als älteste Becken-Eiszeit zuzuweisen.

2. Die bisher mit Mindel verknüpften Schotterstränge zwischen Aitrach und Riss würden zu Sandern des GRG und wären damit nicht mehr Deckenschotter im traditionellen Sinn.

3. Die Haslach-zeitlichen Ablagerungen blieben weiterhin Deckenschotter und zwar wie bisher jüngere Deckenschotter.

Neu ergibt sich folgende zeitlich relative Entwicklung für das Rheingletschergebiet:\#

jünger Größtes Rheinisches Glazial GRG = Hosskirch: Ausschürfung der meisten tiefen Becken, ausgedehnteste Vergletscherung, im NW ehemals Riss, im NE bisher Mindel.

Umlenkung des Alpenrheins und tiefe fluviale Durchtalung

Jüngerer, (tieferer) Deckenschotter = Haslach-Eiszeit

älter (Mindel entfällt als Deckenschotter)

Ausgehend vom Nachweis des Habsburg-Glazials in der Nordschweiz (Keller \& Krayss 2010; Preusser et al. 2011) wurde für das nördliche Bodenseebecken das „Modell eines
Habsburg-Glazials“ aufgestellt mit dem Ziel, stichhaltige Hinweise für diese Eiszeit zu finden (Kapitel 5). Da die räumlichen Ausmasse dieser Vergletscherung in der Nordschweiz in etwa mit denjenigen der Würm-Eiszeit übereinstimmen, wurde für den nördlichen Bodenseeraum eine entsprechende Bandbreite für ein solches Glazial angenommen (Abb. 10), in welchem vorrangig Anzeichen für diese Eiszeit gesucht wurden. Morphologisch in Erscheinung tretende Eisrandbildungen sind nicht zu finden, denn die nachfolgende, weiter reichende Riss-Vergletscherung hat diese überfahren und zerstört oder eingedeckt. Hingegen ergab die Auswertung der bearbeiteten und diskutierten Schlüsselstellen gute Indizien für die angenommene Habsburg-Vergletscherung. Dabei wird von der Akzeptanz einer einzigen Riss-Eiszeit ausgegangen, in der Älteres Riss und Jungriss keine eigenständigen Glaziale sind.

Aus lithostratigraphischen Befunden resultiert die chronologische Einordnung des postulierten Habsburg-Glazials nach dem Größten Rheinischen Glazial GRG = Hosskirch, aber vor der Riss-Eiszeit. Abgesichert wird dies durch die stratigraphische Lage von Paläoböden sowie durch den Nachweis von pollenanalytisch erfassten Interglazialen. Im Liegenden der als Habsburg angesprochenen Sedimente findet sich verschiedentlich das Holstein-Interglazial, im Hangenden ein nicht genauer definierbares Interglazial, das dem Meikirch-Interglazial entsprechen dürfte.

Nachdem zahlreiche lithostratigraphische und/oder morphostratigraphische Indizien und Argumente vorliegen, die im ganzen Rheingletschergebiet das GRG = Hosskirch als ausgedehnteste Vergletscherung und als älteste BeckenEiszeit ausweisen, die Existenz des Habsburg-Glazials als 
Chronostratigraphie des Mittel- und Spätpleistozäns

für die Nordschweiz und das Rheingletschergebiet

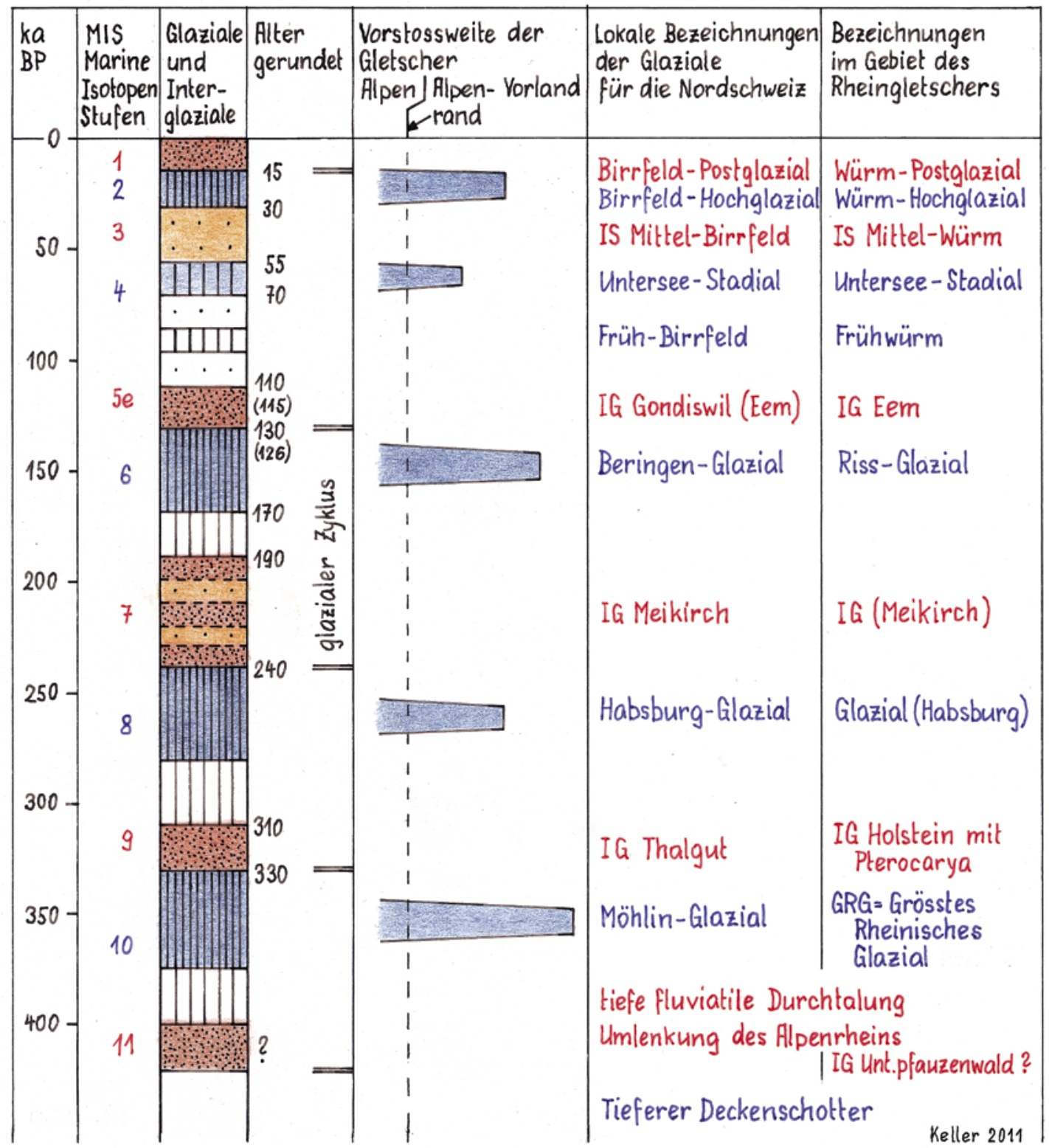

Abb. 18: Chronostratigraphie des Mittel- und Spätpleistozäns der Nordschweiz und des Rheingletschers. Marine Isotopenstufen und Zeitmarken nach LITT et al. (2007) und PREUSSER (2010).

Fig. 18: Chronostratigraphy of the Middle and the Late Pleistocene of Northern Switzerland and of the Rhine Glacier. Marine isotope stages and time marks after LITT et al. (2007) and PREUSSER (2010).

wahrscheinlich erscheinen lassen und die Einstufung dieser Eiszeiten vor der Riss-Eiszeit erfordern, fehlt noch eine Chronostratigraphie. Ausschlaggebend für eine zeitlich absolute Einstufung sind die die Glaziale trennenden Interglaziale. Zeitlich fixiert ist seit längerem das Eem mit 126-110 ka BP, während für das Holstein, noch mit Unsicherheiten behaftet, 320-310 ka BP anzunehmen sind (LitT et al. 2002, 2007). Beide Warmzeiten sind in den Sedimentabfolgen des nördlichen Rheingletschergebiets verschiedentlich nachgewiesen. Das dazwischen liegende Interglazial, das ebenfalls erfasst ist, dürfte dem Meikirch-Interglazial entsprechen, das mit 240-185 ka BP datiert ist (Preusser 2010).

Mit diesen Zeitmarken können die Eiszeiten des Mittelund Spätpleistozäns im nördlichen Bodenseeraum in diesel- be chronostratigraphische Abfolge eingefügt werden, wie sie in KelLER \& KraYsS (2010) für die Nordschweiz aufgestellt wurde. Sie wird hier in der Abb. 18 nochmals aufgeführt. Demnach erfolgten die Großvergletscherungen der BeckenEiszeiten während den als Kaltzeiten ausgewiesenen marinen Isotopenstufen: das Größte Rheinische Glazial GRG in der MIS 10, Habsburg in der MIS 8, Riss in der MIS 6 und das Würm-Hochglazial in der MIS 2.

\section{Danksagung}

Der Autor dankt Edgar Krayss für die langjährige intensive Zusammenarbeit, insbesondere für die zahlreichen zu dieser Arbeit eingebrachten wichtigen Beiträge und für die anre- 
genden, problembezogenen „Streitgespräche“. Er bedauert, dass E. Krayss, altershalber begründet, von der abschliessenden Mitarbeit Abstand nahm. Besten Dank gebührt auch Dietrich Ellwanger für die fruchtbaren Gespräche und klärenden Diskussionen zum Rheingletscher.

\section{Literaturverzeichnis}

BENZ, C. (2003): Der würmeiszeitliche Maximalstand. Digitale Rekonstruktion, Modellierung und Analyse mit einem Geographischen Informationssystem. - Dissertation Geographisches Institut Universität Zürich, $180 \mathrm{~S}$

Bibus, E. (1995): Äolische Deckschichten, Paläoböden und Mindestalter der Terrassen in der Iller-Lech-Platte. - Geologica Bavarica, 99: 135-164.

Bibus, E. \& KösEL, M. (1996): Paläopedologische Klimazeugen zur Untergliederung des Risseiszeiten Komplexes im Rheingletschergebiet. - Eiszeitalter und Gegenwart, 46: 65-90.

Bibus, E. ひ KösEL, M. (2001): Paläoböden von Neufra, Bittelschiess, Baltringen und Rosna. - Unpublizierte Manuskripte der Arbeitsgemeinschaft Alpenvorlandquartär (AGAQ), Tübingen, $7 \mathrm{~S}$.

Doppler, G., Kroemer, E., Rögner, K., Wallner, J., Jerz, H. \& GrotTENTHALER, W. (2011): Quaternary Stratigraphy of Southern Bavaria - E\&G Quaternary Science Journal, 60/2-3: 329-365.

ELLWANGER, D. (1988): Würmeiszeitliche Rinnen und Schotter bei Leutkirch/ Memmingen. - Jahresheft geologisches Landesamt Baden-Württemberg, 30: 207-229.

Ellwanger, D. (1990): Zur Riss-Stratigraphie im Andelsbach-Gebiet (Baden-Württemberg). - Jahresheft geologisches Landesamt BadenWürttemberg, 32: 235-245.

ELLWANGER, D. (2003): Eine landschaftsübergreifende Lockergesteinsgliederung vom Alpenrand zum Hochrhein. - In: Schirmer, W. (Ed.) Landschaftsgeschichte im europäischen Rheinland. - GeoArchäo Rhein, 4: 81-124.

Ellwanger, D., Bibus, E., Bludau, W., Kösel, M. ひ Merkt, J. (1995): Alpenvorland: Oberschwaben, Bodensee und Hochrhein. - In BENDA, L. (Ed.): Das Quartär Deutschlands. - Deutsche Quartärvereinigung: $258-271$

Ellwanger, D., Fiebig, M. \& Heinz, J. (Pollenanalyse Bludau, W.) (1999): Quartärgeologie des mittleren Rheingletschergebietes (Bittelschiess, Höchsten, Hosskirch, Ostrach). - Jahresberichte und Mitteilungen des Oberrheinischen Geologischen Vereins, N.F. 81: 217-230.

Ellwanger, D., Kimmig, B., Simon, T. \& Wielandt-Schuster, U. (2011a) Quartärgeologie des Rheingletschergebietes (Exkursion I am 29. Apri 2011). - Jahresberichte und Mitteilungen des Oberrheinischen Geologischen Vereins, N.F. 93: 387-417.

Ellwanger, D., Wielandt-Schuster, U., Franz, M. \& Simon, T. (2011b) The Quaternary of the southwest German Alpine Foreland (Bodensee Oberschwaben, Baden-Württemberg, Southwest Germany). - E\&G Quaternary Science Journal, 60/2-3: 306-328.

ERB, L. (1934): Erläuterungen zu Blatt Überlingen und Reichenau. - Geologische Spezialkarte von Baden, $120 \mathrm{~S}$.

GöTtLICH, K. \& WERnER, J. (1974): Vorrisszeitliche Interglazialvorkommen in der Altmoräne des östlichen Rheingletschergebietes. - Geologisches Jahrbuch, A18: 49-79.

Graf, H. R. (1993): Die Deckenschotter der Zentralen Nordschweiz. - Dissertation ETH Zürich, $151 \mathrm{~S}$.

Graf, H. R. (2009a): Stratigraphie von Mittel- und Spätpleistozän in der Nordschweiz. Beiträge zur Geologischen Karte der Schweiz, 168. - Bundesamt für Landestopografie swisstopo; 3084 Wabern

GrAF, H. R. (2009b): Stratigraphie und Morphogenese von frühpleistozänen Ablagerungen zwischen Bodensee und Klettgau. - E\&G Quaternary Science Journal, 58/1: 12-53.

GRÜGER, E. \& SCHREINER, A. (1993): Riss/Würm- und würmzeitliche Ablagerungen im Wurzacher Becken (Rheingletschergebiet). - N. Jahrbuch Geologie und Paläontologie, 189: 81-117.

HAAG, T. (1982): Das Mindelglazial des nördlichen Rheingletschergebietes zwischen Riss und Iller. - Jahresberichte und Mitteilungen des Oberrheinischen Geologischen Vereins, N.F: 64: 225-266.

HoFmanN, F. (1994): Beobachtungen zur Quartärgeologie des Schaffhause Klettgaus (Schweiz). - Eclogae geologicae Helvetiae, 87/1: 241-263.

JeAnNet, A. (1923): Les charbons feuilletés de la vallée de la Linth entre les lacs de Zurich et de Walenstadt. - In: Baumberger, E., Gerber, E. JeAnnet, A. \& Weber, J.: Die diluvialen Schieferkohlen der Schweiz. Beiträge zur Geologie der Schweiz, geotechnische Serie VIII: 106-370.
Keller, O. (1994): Entstehung und Entwicklung des Bodebnsees - ein geologischer Lebenslauf. - In: Maurer, H. (Ed.): Umweltwandel am Boden see. - UVK: 33-92; St. Gallen.

Kellek, O. (2009): Als der Alpenrhein sich von der Donau zum Oberrhein wandte. - Schriften des Vereins für Geschichte des Bodensees und seiner Umgebung, 127: 193-208.

Kellek, O. \& Krayss, E. (1982): Methoden zur Rekonstruktion eiszeitlicher Vorland- und Talgletscher. - Physische Geographie, Geographisches Institut Universität Zürich, 1: 127-136.

Keller, O. \& Krayss, E. (1993): The Rhine-Linth-Glacier in the Upper Wurm: A model of the last alpine Glaciation. - Quaternary International, 18: 15-27.

Keller, O. \& Krayss, E. (1998): Datenlage und Modell einer Rhein-LinthVorlandvergletscherung zwischen Eem-Interglazial und Hochwürm: GeoArcheoRhein 2: 121-138; Münster.

Keller, O. ひ Krayss, E. (1999): Quartär und Landschaftsgeschichte. - Erläuterungen zur Geologischen Übersichtskarte des Kantons Thurgau. - Mitteilungen der Thurgauischen Naturforschenden Gesellschaft, 55: 39-67.

Keller, O. ¿ Krayss, E. (2005): Der Rhein-Linth-Gletscher im letzten Hochglazial. - Vierteljahresschrift der Naturforschenden Gesellschaft in Zürich, 150/1-2: 19-32 und 150/3-4: 69-85.

Keller, O. \& Krayss, E. (2010): Mittel- und spätpleistozäne Stratigraphie und Morphogenese in Schlüsselregionen der Nordschweiz. - E\&G Quaternary Science Journal, 59/1-2: 88-119.

LGRB (2003) (Bearbeiter: VILLINGER, E.): Quartär in Baden-Württemberg Klima/lithostratigraphisches Übersichtsschema. - Landesamt für Geologie, Rohstoffe und Bergbau Baden-Württemberg; Freiburg i. Br.

LGRB (2005) (Bearbeiter: EllwANGER, D. ¿ Villinger, E.): Quartär in Baden-Württemberg, Klima/lithostratigraphisches Übersichtsschema. Landesamt für Geologie, Rohstoffe und Bergbau Baden-Württemberg; Freiburg i. Br.

Litt, T., Ellwanger, D., Villinger, E. \& Wansa, S. (2002): Das Ouartär in der Stratigraphischen Tabelle von Deutschland 2002. - Newsletter Stratigraphie 41: 385-399.

Litt, T., Behre, K. E., Meyer, K. D., Stephan, H. J. ¿ Wansa, S. (2007): Stratigraphische Begriffe für das Quartär des norddeutschen Vereisungsgebietes. - Eiszeitalter und Gegenwart, 56/1-2: 7-65.

Miara, S.,ZÖLler, L., RÖGNER, K. \& RousseAU, D. (1996): Quartäraufschlüsse bei Baltringen/Riss und Gliederung des Riss-Komplexes - neue stratigraphische, pedologische und geochronologische Aspekte. - Zeitschrift für Geomorphologie, N.F. 40: 209-226.

PencK, A. (1939): Klettgauer Pforte und Bodensee. - Schriften des Vereins für Geschichte des Bodensees und seiner Umgebung, 66: 117-139.

Penck, A. \& Brückner, E. (1909): Die Alpen im Eiszeitalter, 1999 S. - Leipzig (Tauchnitz).

Preusser, F. (1999): Luminescence dating of fluvial sediments and overbank deposits from Gossau, Switzerland: fine grain dating. - Quaternary Science Reviews 18: 217-222

Preusser, F. (2010): Stratigraphische Gliederung des Eiszeitalters in der Schweiz (Exkursion E am 8. April 2010). - Jahresberichte und Mitteilungen des Oberrheinischen Geologischen Vereins, N.F. 92: 83-98.

Preusser, F., Drescher-Schneider, R., Fiebig, M. \& Schlüchter, C (2005): Re-interpretation of the Meikirch pollen record, Swiss Alpine Foreland, and implications for Middle Pleistocene chronostratigraphy. - Journal of Quaternary Science, 20: 607-620.

Preusser, F., Graf, H. R., Keller, O., Krayss, E. \& Schlüchter, C. (2011) Quaternary glaciation history of northern Switzerland. - E\&G Quaternary Science Journal, 60/2-3: 282-305.

Rögner, K. (1998): Die vier Felder von Memmingen. - Münchner Geographische Abhandlungen, Reihe A, Band A49: 15-26.

Schindler, C. (1985): Geologisch-geotechnische Verhältnisse in Schaffhausen und Umgebung. - Beiträge zur Geologie der Schweiz, Kleinere Mitteilungen, 74, ETH Zürich: $119 \mathrm{~S}$.

Schindler, C. (2004): Zum Quartär des Linthgebietes zwischen Luchsingen, dem Walensee und dem Zürcher Obersee. - Beiträge zur Geologischen Karte der Schweiz, 159 S. - Bundesamt für Landestopografie swisstopo; 3084 Wabern.

SCHLÜCHTER, C. (1988): A non-classical summary of Quaternary stratigraphy in the northern alpine Foreland of Switzerland. - Bulletin de la Société neuchâteloise de géographie, 32: 143-157.

SCHLÜCHTER, C. (1989): Thalgut: Ein umfassendes eiszeitstratigraphisches Referenzprofil im nördlichen Alpenvorland. - Eclogae geologicae Helvetiae, $82: 277-284$.

Schlüchter, C., Maisch, M., Suter, J., Fitze, P., Keller, W.A., Burga, C.A. \& Winistorf, E. (1987): Das Schieferkohlenprofil von Gossau 
(Kanton Zürich) und seine stratigraphische Stellung innerhalb der letzten Eiszeit. - Vierteljahresschrift der Naturforschenden Gesellschaft in Zürich, 132/2: 135-174.

Schreiner, A. (1974): Erläuterungen zur Geologischen Karte des Landkreises Konstanz mit Umgebung, 286 S. - Geologisches Landesamt BadenWürttemberg; Freiburg i. Br.

SchreIner, A. (1980): Zur Quartärgeologie in der Umgebung des Eem-Interglazials von Krumbach/Saulgau (Baden-Württemberg). - Geologisches Jahrbuch, A56: 5-43.

Schreiner, A. (1985): Erläuterungen zu Blatt 7824 Biberach Nord. - Geologische Karte Baden-Württemberg 1:25'000: 1-76.

SchreIner, A. (1989): Zur Stratigraphie der Risseiszeit im östlichen Rheingletschergebiet (Baden-Württemberg). - Jahresheft geologisches Landesamt Baden-Württemberg, 31: 183-196.

Schreiner, A. (1992): Einführung in die Quartärgeologie. - Schweizerbart Stuttgart: $257 \mathrm{~S}$

SchreInER, A. (1996): Die Einführung der Haslacheiszeit und die 3-Teilung der Risseiszeit im östlichen Rheingletschergebiet (SW-Deutschland). Eclogae geologicae Helvetiae, 89/3: 991-1005.

SchreINeR, A. \& EBel, R. (1981): Quartärgeologische Untersuchungen in de Umgebung von Interglazialvorkommen im östlichen Rheingletschergebiet (Baden-Württemberg). - Geologisches Jahrbuch A59: 3-64.

SchreIner, A. \& HAAG, T. (1982): Zur Gliederung der Risseiszeit im östlichen Rheingletschergebiet (Baden-Württemberg). - Eiszeitalter und Gegenwart, 32: 137-161.

SzENKLER, C. \& Bock, H. (1999): Quartärgeologie und Rohstoffgeologie im Singener Beckenkomplex - westliches Rheingletschergebiet (Hegau,
Landkreis Konstanz). - Jahresberichte und Mitteilungen des Oberrheinischen Geologischen Vereins, N.F. 81: 183-216.

VILlinger, E. (1985): Geologie und Hydrogeologie der pleistozänen Donaurinnen im Raum Sigmaringen-Riedlingen. - Abhandlungen geologisches Landesamt Baden-Württemberg, 11: 166-174.

Villinger, E. (2003): Zur Paläogeographie von Alpenrhein und oberer Donau. - Zeitschrift der Deutschen Geologischen Gesellschaft, 154/2-3: 193-253.

Villinger, E. (2011): Geologische Übersichts- und Schulkarte von BadenWürttemberg 1 : 1'000'000. - Landesamt für Geologie, Rohstoffe und Bergbau LGRB, Freiburg i. Br.

Weidenbach, F. mit Beiträgen von Graul, H., Kiderlen, H., Schreiner, A., HAAG, T. (1988): Geologische Übersichtskarte des Iller-Rissgebiets. Geologisches Landesamt Baden-Würtemberg.

Welten, M. (1982): Pollenanalytische Untersuchungen im Jüngeren Quartär des nördlichen Alpenvorlandes der Schweiz. - Beiträge zur Geologischen Karte der Schweiz, 156: 1-174. - Bundesamt für Landestopografie swisstopo; 3084 Wabern.

Wenninger, A. (1994): Erläuterungen zu Blatt 8126 Leutkirch im AllgäuOst, 1. Auflage. - Geologische Karte Baden-Württemberg 1:25`000, 147 S.

Werner, J. (1975): Erläuterungen zu Blatt 8020 Messkirch, 1. Auflage. - Geologische Karte Baden-Württemberg 1:25'000, 209 S.

WERNER, J. (1994): Erläuterungen zu Blatt 8020 Messkirch, 2. überarbeitete Auflage. - Geologische Karte Baden-Württemberg 1:25'000, 214 S.

Winistorf, E. (1987): Das Schieferkohlenprofil von Gossau (Kanton Zürich) und seine stratigraphische Stellung innerhalb der letzten Eiszeit. - Vierteljahresschrift der Naturforschenden Gesellschaft in Zürich, 132: $135-174$. 